\title{
Utilization of synthetic nano-cryptomelane for enhanced scavenging of cesium and cobalt ions from single and binary solutions
}

\author{
M. Ghaly ${ }^{1}$ S. S. Metwally ${ }^{1}$ E. A. El-Sherief ${ }^{1}$-E. A. Saad ${ }^{2} \cdot$ R. O. Abdel Rahman ${ }^{1}$
}

Received: 23 December 2021 / Accepted: 3 February 2022 / Published online: 3 March 2022

(c) The Author(s) 2022

\begin{abstract}
The feasibility of using nano-cryptomelane for elimination of cobalt and cesium metal ions from their single and binary solutions was studied. In this respect, the material was prepared and characterized to confirm its chemical composition and structure. Results illustrate that the synthesized nano-cryptomelane has a tunnel structure with particle size ranged between 4 and $6 \mathrm{~nm}$. The material feasibility was detected by conducting a series of batch experiments for determination of the kinetic and equilibrium performance of the removal process. All characteristic Raman bands for $\mathrm{Mn}-\mathrm{O}$ lattice vibrations within the $(2 \times 2)$ tunnel structure of $\mathrm{MnO}_{6}$ octahedral are observed which confirm formation of nano-cryptomelane. The specific surface area (SSA) for nano-cryptomelane was calculated and equal to $299.03 \mathrm{~m}^{2} / \mathrm{g}$ while the surface fractal information $\left(D_{\mathrm{s}}\right)$ was 2.53 . The process sensitivity to changes of $\mathrm{H}^{+}$concentration is attributed to changes in structural elements-species distribution at the solid/aqueous interface. The $\mathrm{pH}$ optimum value was desired at $\mathrm{pH} 5$ for exchange of $\mathrm{Cs}^{+}$and/or $\mathrm{Co}^{2+}$ with $\mathrm{K}^{+}$ions. The equilibrium studies show that Langmuir isotherm model was more fitted to the experimental data than that of Freundlich model.
\end{abstract}

Keywords Nano-cryptomelane $\cdot$ Binary solution $\cdot$ Cobalt $\cdot$ Cesium $\cdot$ Sorption

\section{Introduction}

The amassing of hazardous metal ions through the food chain accompanied with a harmful effects for the human health thus to reduce these effects and for environmental protection, sequestration of these contaminates from wastewater is very important process. Estimation and removal of these toxic contaminants are essential to meet safety requirements and the environmental standards [1-3]. Both of cobalt and cesium ions are broadly utilized in the nuclear power plant and coal-fired power plants as well as and in various applications of industry such as metallurgical, battery manufacturing, mining, electroplating, paints, grinding wheels, petroleum, pigments, and electronics [4-7]. Higher cobalt concentration has harmful impacts on the human beings; it leads to lung irritations, asthma, pneumonia, weight loss,

M. Ghaly

marmora.ghaly@yahoo.com

1 Hot Laboratories Center, Egyptian Atomic Energy Authority, Cairo 13759, Egypt

2 Department of Chemistry, Faculty of Science, Ain Shams University, Cairo, Egypt paralysis, diarrhea, vomiting, damage thyroid hormone and liver and nausea[8-13]. Due to similarity of cesium-134 to sodium thus ingestion of cesium leads to its deposition in the soft tissues all over the body which in turn cause internal hazards[14-16].

Coagulation, evaporation, electrodialysis, chemical precipitation, chelation, reverse osmosis, membrane filtration, solvent extraction, biosorption, and ion exchange are various methods suggested for the elimination of toxic contaminants from wastewater [17-20]. Ion exchange process has several advantages more than other methods including high efficiency, cost-effectiveness, production of less toxic sludge, etc. [21, 22].

Several sorbent materials can be used for the elimination of these toxic contaminants from aqueous waste. Nano sized metal oxides (NMOs) have a high specific tendency for sorption of metal ions from liquid solutions; the most widely studied ones are aluminum oxides, titanium oxides, cerium oxides and manganese oxides. NMOs exist in different morphologies such as particles, tunnels and others. Both of size and shape of NMOs are important factors that affects greatly their sorption performance. Several efficient preparation procedures are widely studied to obtain a highly stable, 
shape-controlled and mono disperse NMOs[23]. Nanosized manganese oxides (NMnOs) are widely studied for environmental concerns as birnessite and cryptomelane [24, 25].

Hydrous manganese oxide (HMO) and mixed-valance manganese oxides are most common NMnOs [23]. Mixedvalence manganese oxides considered as potential interesting sorbents for cations and usually present as octahedral molecular sieve (OMS). Cryptomelane considered as an example of mixed-valence octahedral molecular sieve (K-OMS-2) manganese oxide, the main oxidation states of manganese are $\mathrm{Mn}^{4+}$ and $\mathrm{Mn}^{3+}$ [23].The OMS-2 group building unit is $\mathrm{MnO}_{6}$ octahedral which in turn form a single octahedral chain through participating two opposite edges after that a double chain is resulted via combination of two neighbor single chains, finally, four chains corner connected forming a one-dimensional $2 \times 2$ open tunnel structure with a diameter of about $460 \mathrm{pm}$ [26-28].

Cryptomelane has two ion exchange sites; particular sites found interior tunnel structure and the unspecific sites, ion exchangeouter surface sites. The exchangeable cation, $\mathrm{K}^{+}$, is located interior tunnel structure to stabilize negative charge balance that originating from $\mathrm{Mn}^{3+}$ in an otherwise perfect $\mathrm{Mn}^{4+} \mathrm{O}_{2}$ structure. Several synthesis procedures have been published for synthesis of nano-cryptomelane such as sol-gel method [29] hydrothermal treatment procedure for birnessite [30] and oxidation of $\mathrm{Mn}^{2+}$ by $\mathrm{KMnO}_{4}, \mathrm{H}_{2} \mathrm{O}_{2}$ or $\mathrm{K}_{2} \mathrm{~S}_{2} \mathrm{O}_{8}$ in acidic refluxing conditions [31]. Nano-cryptomelane considers as selective ion exchanger due to its porous and tunnel structure, hydrophobic nature and mixed valence of manganese [28].The morphology of synthesized nanocryptomelane (rod-like, fibrous-like and nest-like morphologies) depends incredibly on the preparation method (solid state, reflux and hydrothermal method) [32].

The previous work illustrated that nano-cryptomelane can be synthesized using several methods such as sol-gel route, hydrothermal treatment procedure of birnessite and oxidation of $\mathrm{Mn}^{2+}$ by $\mathrm{KMnO}_{4}, \mathrm{H}_{2} \mathrm{O}_{2}$ or $\mathrm{K}_{2} \mathrm{~S}_{2} \mathrm{O}_{8}$ in acidic refluxing conditions. The main target of this work is utilization of synthesized nano-cryptomelane for retention of cesium and cobalt metal ions from single and binary solutions.

\section{Experimental}

\section{Materials and reagents}

Manganese sulfate, acetic acid and potassium permanganate, $\mathrm{KMnO}_{4}$, were obtained from Alpha Chemika, Euromedex and El-Nasr Company for chemicals, respectively and used to prepare nano-cryptomelane. Cesium chloride and cobalt chloride were obtained from LOBA. $\mathrm{NaOH}$ and $\mathrm{HCl}$ were obtained from Fluka and used for $\mathrm{pH}$ adjustment.

\section{Preparation of nano-cryptomelane}

As mentioned in the previous work [28],the oxidation method was the selected procedure for preparation of nanocryptomelane under acidic conditions [33]. The preparation method involved preparing $1.0 \mathrm{~L}$ of $0.2 \mathrm{M} \mathrm{MnSO}_{4}$ in $2 \mathrm{M}$ acetic acid. The acidified $\mathrm{MnSO}_{4}$ was added over permanganate solution $(0.35 \mathrm{M})$ pre-dissolved in $800 \mathrm{~mL}$ deionized water over a time period of $2 \mathrm{~h}$ at $65{ }^{\circ} \mathrm{C}$ in 4.0 Lbeaker with vigorous stirring. An aluminum hinder was used above the beaker and a hole was done to permit a thermometer to be inserted into the beaker. After $2 \mathrm{~h}$, temperature was raised to $80^{\circ} \mathrm{C}$ and held for about 10 min then a dark black manganese oxide was formed. The obtained mixture was gradually cooled until reach the room temperature and left overnight for the aging process after that wet-aged for $48 \mathrm{~h}$ at $7{ }^{\circ} \mathrm{C}$. The resulted dark black MNOs were centrifuged at $6000 \mathrm{rpm}$, washed many times using bi-distilled water and finally, freeze-dried for 8 days, Fig. 1.

\section{Removal studies}

$10 \mathrm{~mL}$ of $10^{-3} \mathrm{M} \mathrm{Co}^{2+}$ or $\mathrm{Cs}^{+}$metal ion solution was agitated with $0.05 \mathrm{~g}$ nano-cryptomelane and centrifuged to separate the liquid and solid phases. Same molar ratio (1:1) of $\mathrm{Co}^{2+}$ and $\mathrm{Cs}^{+}$was used to prepare $10^{-3} \mathrm{M}$ binary solution. The elemental analysis for the clear diluted liquid was approached using atomic absorption spectroscopy.

\section{Synthesis of multi-system solution}

A binary stock solution of $0.02 \mathrm{M}$ ionic strength was prepared through dissolving same molar ratio, 1:1 of cesium and cobalt ions. The metal ion concentrations in the solutions were determined using an atomic absorption spectrophotometer (Buck Scientific) model 210 VGP, USA, an airacetylene flame.

\section{Structural and surface area investigation of Nano-cryptomelane}

$\mathrm{X}$-ray diffraction (XRD) results were determined by $\mathrm{CuK} \alpha$ radiation at $40 \mathrm{kV}$ using Schimadzo X-ray powder diffractometer and processed by using Match software. Ramanscattering data were performed at Raman shift between 100 and $3600 \mathrm{~cm}^{-1}$ at room temperature with spectral resolution of $0.5 \mathrm{~cm}^{-1}$, equipped using a Peltier-cooled charge-coupled device $(1152 \times 298$ pixels). The excitation wavelength of the spectrum was $632.81 \mathrm{~nm}$ and was supplied using a $\mathrm{He}-\mathrm{Ne}$ laser placed on an Olympus high-stability BXFM confocal microscope. Nitrogen adsorption-desorption isotherms of nano-cryptomelane were used for determination of SSA by 
Fig. 1 Synthesis of Nano-Cryptomelane

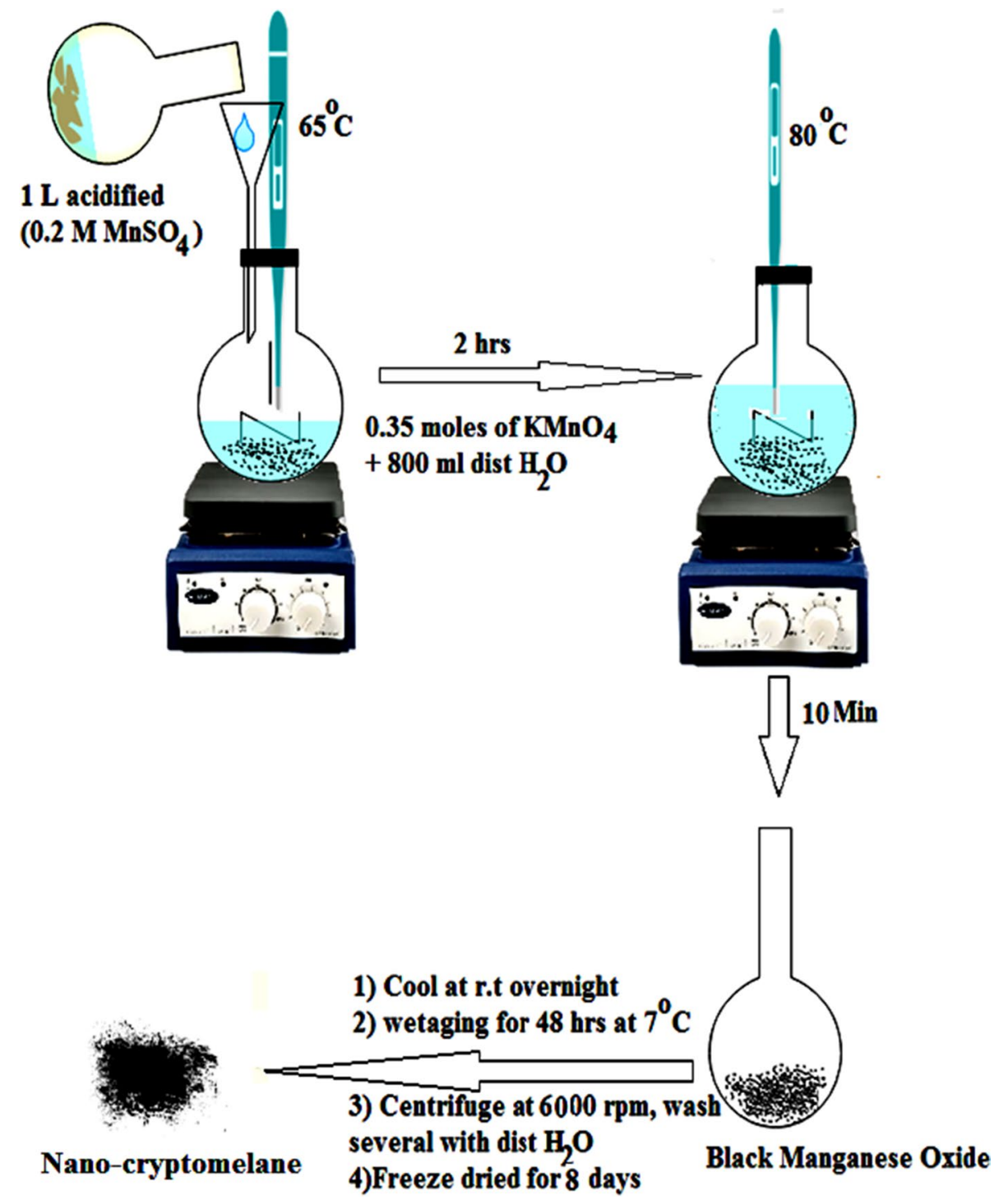

means of a fully automated surface area analyzer (Quantachrome Corporation, Nova station 2010 instrument, USA).

Brunauer-Emmett-Teller (BET) model can be given as [34]:

$\frac{1}{V\left(\frac{P^{0}}{P}-1\right)}=\frac{1}{C \cdot V_{\mathrm{m}}}+\frac{C-1}{C-V_{\mathrm{m}}} \cdot \frac{P^{0}}{P}$,

where $V$ refers to volume of adsorbed nitrogen at equilibrium pressure $P\left(\mathrm{~cm}^{3} / \mathrm{g}\right), P^{0}$ is the saturation pressure of nitrogen, $C$ is the characteristic constant. $V_{\mathrm{m}}$ is volume of nitrogen of the monolayer coverage $\left(\mathrm{cm}^{3} / \mathrm{g}\right)$, can be determined from slope and intercept of the linear fitting of the plot $1 /$ $\left[V\left(P^{0} / P-1\right)\right]$ against the relative pressure $\left(P / P^{0}\right)$. Value of SSA was then determined from the calculated value of $V_{\mathrm{m}}$, volume occupied by one mole of nitrogen gas and the sample mass and Avogadro's number[35]. In this work, modified Frenkel-Halsey-Hill (FHH) model [36] is adopted for estimating value of $D_{\mathrm{s}}$ of sorbents using adsorption isotherm data. The logarithmic form for the modified (FHH) model can be described as follows:

$\ln \left(\frac{V}{V_{\mathrm{m}}}\right)=A \cdot \ln \left(\ln \left(\frac{P^{\mathrm{O}}}{P}\right)\right)+C$,

where $A$ is the power law exponent that is reliant in $D_{\mathrm{s}}$ value and the adsorption mechanism. It is worth mentioning that when the pore surface dimension $(D)$ is obtained, the relevant pressure ranged between 0 and 0.3 . Then, the surface fractal information $\left(D_{\mathrm{s}}\right)$ value may be determined from the following equation:

$D_{\mathrm{s}}=3+A$. 


\section{Results and discussion}

As mentioned in the past work, particle size of the synthesized nano-cryptomelane was ranged between 4 and $6 \mathrm{~nm}$ [28].

\section{Structural investigation of nano-cryptomelane}

\section{X-ray diffraction analysis}

XRD pattern for nano-cryptomelane is shown in Fig. 2a, the pattern reveals the existence of six diffraction peaks recorded at $2 \theta$ of $12.8^{\circ}, 18.5^{\circ}, 28.9^{\circ}, 37.5^{\circ}, 42^{\circ}$ and $50^{\circ}$ which are specific peaks for nano-cryptomelane [29, 37].

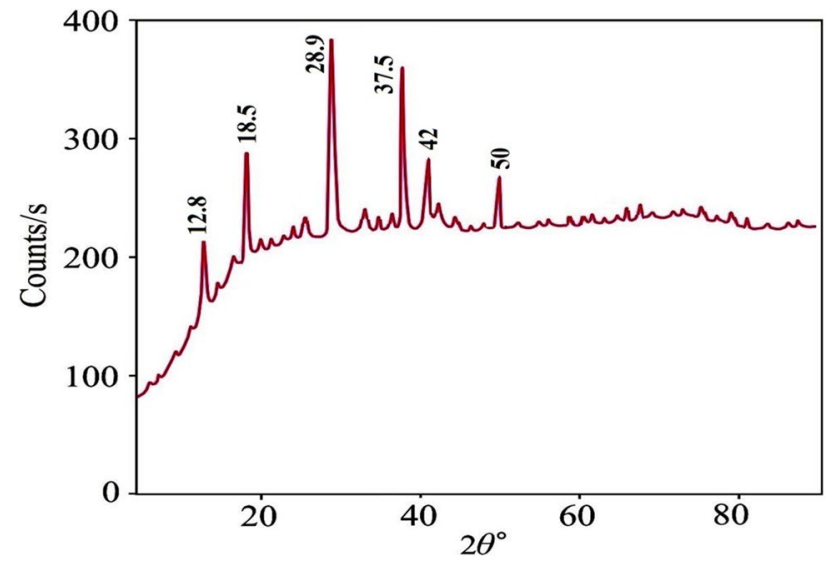

a XRD of nano-cryptomelane

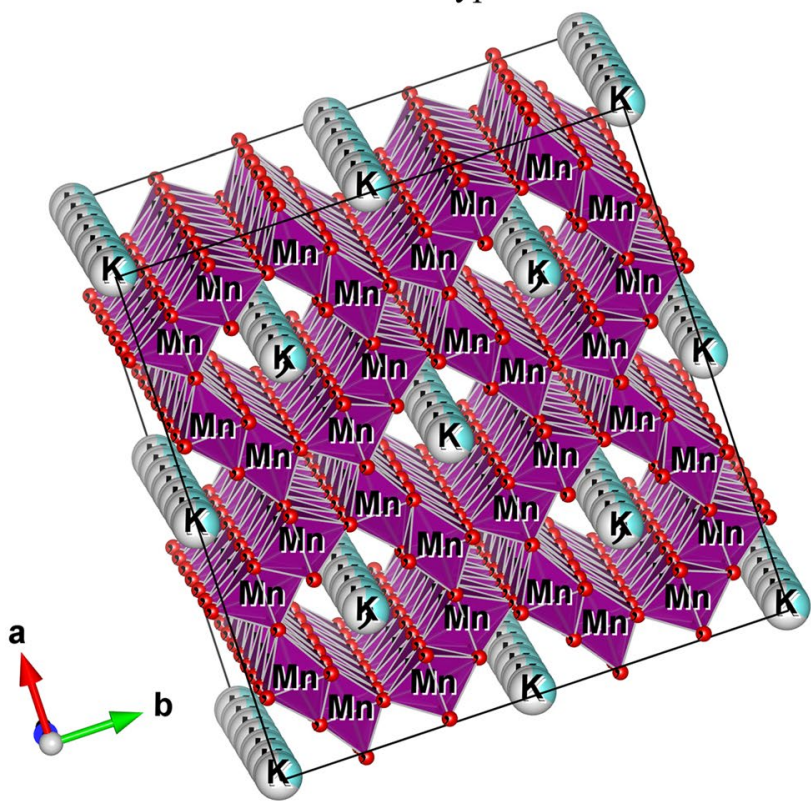

b Identified crystalline structure

Fig. 2 a XRD of nano-cryptomelane. b Identified crystalline structure
VESTA program was used to identify the crystalline structure of nano-cryptomelane, Fig. 2b.[38].

\section{Raman spectroscopy}

Raman scattering spectrum of nano-cryptomelane is illustrated in Fig. 3. Seven Raman bands are detected at 183, 286, 330, 386, 512, 574, and $753 \mathrm{~cm}^{-1}$ which are specific bands of the $\mathrm{Mn}-\mathrm{O}$ lattice vibrations within the $(2 \times 2)$ tunnel structure of $\mathrm{MnO}_{6}$ octahedral [39]. The low-frequency Raman bands at 183 and $286 \mathrm{~cm}^{-1}$ are ascribed to an external vibration that derives from the translational motion of the $\mathrm{MnO}_{6}$ octahedral; the Raman bands at 330 and $386 \mathrm{~cm}^{-1}$ are specific to the Mn-O bending vibrations; The Raman bands located at 512 and $574 \mathrm{~cm}^{-1}$ may attributed to displacement of the oxygen atoms relative to the manganese atoms along the octahedral chains. The high-frequency Raman band at $753 \mathrm{~cm}^{-1}$ corresponds to the anti-symmetric Mn-O stretching vibrations.

\section{Surface area measurements (SSA)}

Figure 4a shows $\mathrm{N}_{2}$ adsorption-desorption isotherm of nanocryptomelane. At low relative pressure region $\left(P / P^{0}<0.1\right)$, nano-cryptomelane display a steep uptake of nitrogen, on the other side at relatively higher pressure the hysteres is loop between 0.8 and $1 P / P^{0}$ suggests $\mathrm{N}_{2}$ capillary condensation in mesopores, representing the existence of mesoporous structures in nano-cryptomelane[40]. Figure $4 \mathrm{~b}$ shows the linear fitting for the plot of $1 /\left[V\left(P^{0} / P-1\right)\right]$ against relative pressure $\left(P / P^{0}\right)$ where $V_{\mathrm{m}}$ value was detected using the slope and the intercept data. The value the SSA compared to other scavengerswas illustrated in Table 1 . Value of $D_{\mathrm{s}}$ was calculated using slope of the fitting curve of plot of $\ln \left(V / V_{\mathrm{m}}\right)$ versus $\ln \left(\ln \left(P^{0} / P\right)\right)$ and detected to be 2.53 .

\section{Effect of initial effluent $\mathrm{H}^{+}$ion concentration (pH)}

The elimination efficiency of cesium and cobalt ions from single and binary solutions was studied at $\mathrm{pH}$ range of 1 to 6 ; the alkaline conditions were excluded to avoid complications of precipitation. The data reveals that sorption capacities of cesium and cobalt ions from single and binary systems increase with increasing $\mathrm{pH}$ of the effluent and the pH optimum value was 5.0, Fig. 5a. This may be attributed to the fact that at low $\mathrm{pH}$ values, a competition between $\mathrm{H}^{+}$ions and cations for nano-cryptomelane exchange sites. The zero point charge of nano-cryptomelane, $\mathrm{pH}_{\mathrm{zpc}}$, was detected and equal to 4.0.The surface of nano-cryptomelane possess a negative charge above $\mathrm{pH}_{\mathrm{zpc}}$ and positive below the $\mathrm{pH}_{\mathrm{zpc}}$. Therefore, the sorption of cobalt and cesium ions at $\mathrm{pH}$ greater than 4 should be high, Fig. 5b. The relation 
Fig. 3 Raman scattering spectrum of nano-cryptomelane

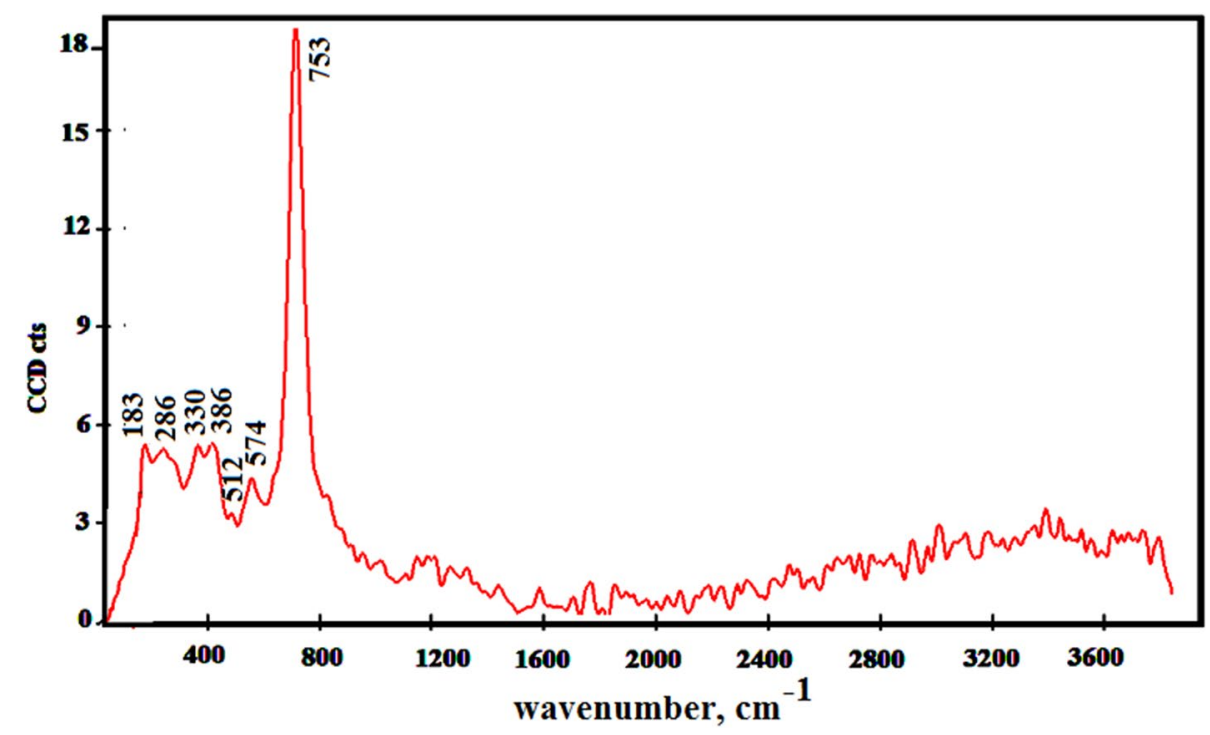

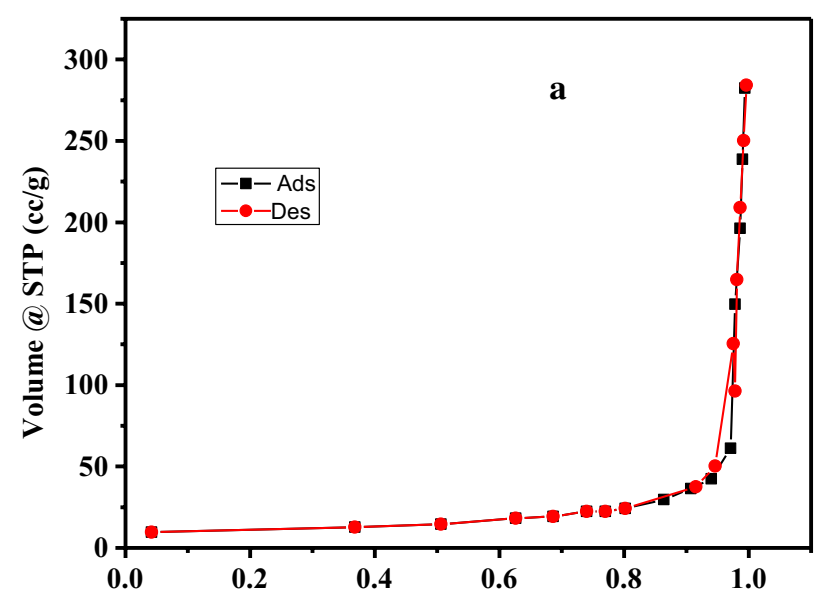

Relative pressure, $\mathbf{P} / \mathbf{P}^{\mathbf{0}}$

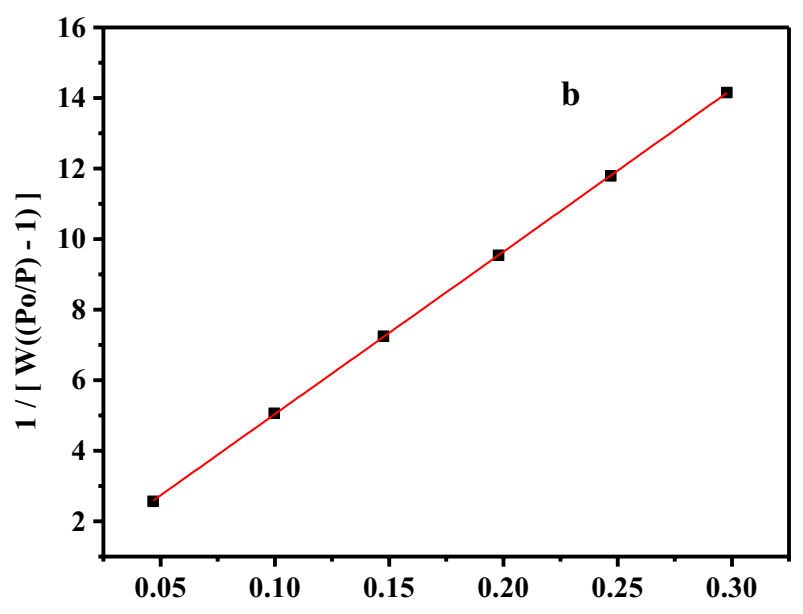

Relative pressure, $\mathbf{P} / \mathbf{P}^{\mathbf{0}}$

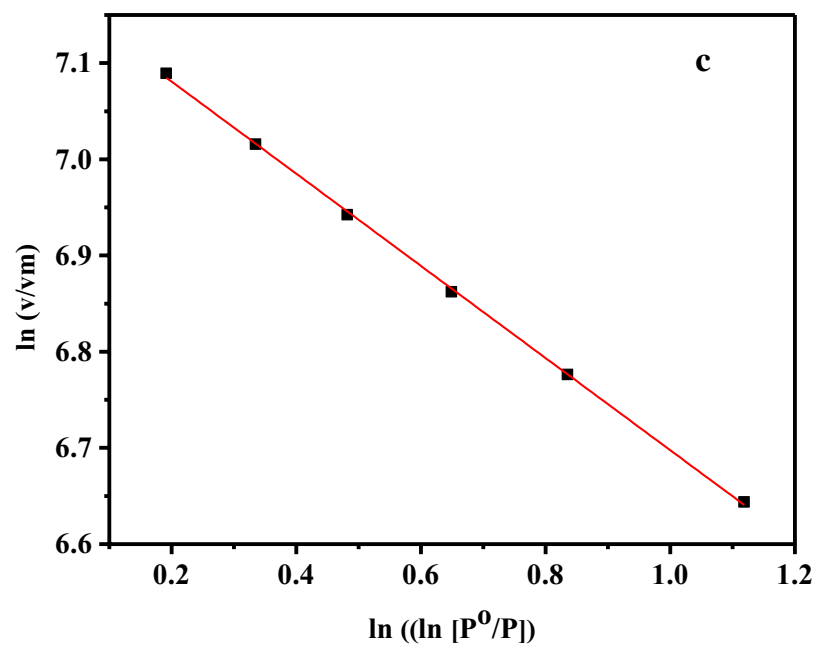

Fig. 4 a $\mathrm{N}_{2}$ adsorption/desorption isotherms of Nano-cryptomelane, b Fitting curve for uptake of nitrogen of a monolayer coverage, and c)Fitting curve for surface fractal dimension 
Table 1 Comparison of the SSA, sorption capacity, particle size, and permanent negative charge for different inorganic sorbents

\begin{tabular}{|c|c|c|c|c|c|c|}
\hline Material & $\mathrm{SSA}\left(\mathrm{m}^{2} / \mathrm{g}\right)$ & $\begin{array}{l}\text { Sorption } \\
\text { capacity } \\
(\mathrm{meq} / \mathrm{g})\end{array}$ & Measuring method & Particle size $(\mu \mathrm{m})$ & $\begin{array}{l}\text { Permanent nega- } \\
\text { tive charge, (meq/ } \\
\mathrm{m}^{2} \text { ) }\end{array}$ & Refs \\
\hline Nano-cryptomelane & 299.03 & 4.65 & BET, Na-method & $0.004-0.006$ & 0.0155 & This work \\
\hline K-Birnessite & 16.3 & 1.8 & BET, Na-method & $0.8-1.5$ & 0.11 & {$[23]$} \\
\hline Amorphous manganese oxide & 14.8 & 0.34 & BET, N/A & - & 0.02 & {$[39]$} \\
\hline Magnetically modified zeolite & 25.15 & 0.82 & Saturation* & - & 0.03 & {$[40]$} \\
\hline Gismondine-type zeolite & $10-13$ & $2.25-2.37$ & - & $12-21 * *$ & $0.18-0.23$ & [41] \\
\hline Treated natural zeolite & $12.9-112$ & $0.145-8.45$ & Saturation* & - & $0.01-0.7$ & {$[42]$} \\
\hline Sepiolite $\left(\mathrm{Si}_{12} \mathrm{Mg}_{8} \mathrm{O}_{30}(\mathrm{OH})_{6}\left(\mathrm{OH}_{2}\right)_{4}{ }_{8} \mathrm{H}_{2} \mathrm{O}\right)$ & 17.34 & 0.12 & BET & - & 0.007 & {$[43]$} \\
\hline Magnetic nano-zeolite & 1380 & 4.44 & BET, Na-method & 0.038 & 0.003 & {$[44]$} \\
\hline $\mathrm{Mg} / \mathrm{Fe}$ hydrotalcite & - & 0.089 & Na-method & $2-3$ & - & [45] \\
\hline
\end{tabular}

*Langmuir monolayer saturation capacity

**D50 value

of $\log K_{\mathrm{d}}$ as a function of $\mathrm{pH}$ was found to fit the following relations:

For $\mathrm{Cs}^{+}$

a) Single solution $\log K_{\mathrm{d}}=0.6 \mathrm{pH}-2.1$,

b) Binary solution $\log K_{\mathrm{d}}=0.6 \mathrm{pH}-2.4$,

For $\mathrm{Co}^{2+}$

a) Single solution $\log K_{\mathrm{d}}=0.5 \mathrm{pH}-2.2$,

b) Binary solution $\log K_{\mathrm{d}}=0.5 \mathrm{pH}-2.5$,

The slopes of the straight lines are corresponding to the valence of sorbed metal ions Fig. 5c. Values of $n$ for cesium and cobalt metal ions either in single solutions or in binary solutions were about 1 which reflects that both of them are sorbed as monovalent species. The speciation of $\mathrm{Co}^{2+}$ and $\mathrm{Cs}^{+}$at different $\mathrm{pH}$ values in the aqueous solution are illustrated in Fig. 5d which illustrates that at the $\mathrm{pH}$ optimum value, $\mathrm{pH} 5$, both of $\mathrm{Co}^{2+}$ and $\mathrm{Cs}^{+}$are sorbed as monovalent species. Nano-cryptomelane has a higher affinity towards $\mathrm{Cs}^{+}$more than $\mathrm{Co}^{2+}$ which may attributed to fact that the atomic radius of $\mathrm{Co}(\mathrm{OH})^{+}$is larger than that of $\mathrm{Cs}^{+}$thus the movement of monovalent cobalt species from the bulk of solution to the surface of nano-cryptomelane is slower than that of $\mathrm{Cs}^{+}[41,42]$.

\section{Effect of contact time and temperature}

Corresponding to Figs. 7a and 8a and Tables 2 and 3 the experimental data indicate that sorption process more fitted to pseudo-second-order reaction which indicates that sorption process is chemisorption[44].Sorption of $\mathrm{Cs}^{+}$and $\mathrm{Co}^{2+}$ from single and binary solutions onto nano-cryptomelane was studied as a function of shaking time over time intervals of 1-180 min as shown in Fig. 6. Experimental data illustrate that the removal performance of $\mathrm{Cs}^{+}$and $\mathrm{Co}^{2+}$ either from single or binary solutions increase by increasing the time of contact and equilibrium is obtained after about 45 min for all solutions. At beginning of the cation elimination process, the quantity sorbed increased rapidly which may be attributed to presence of more sorbing sites, after 45 min, equilibrium was obtained and sorbing sites are approximately saturated. Results show that the quantity sorbed of $\mathrm{Co}^{2+}$ and $\mathrm{Cs}^{+}$increased with raising temperature which reflects the endothermic nature of sorption process. The percent of metal ion elimination may be detected using the following equation.

Elimination percent $=\frac{\mathrm{C}_{i}-\mathrm{C}_{t}}{\mathrm{C}_{i}} \times 100$,

where $\mathrm{C}_{i}$ and $\mathrm{C}_{t}$ are metal ion concentration in solutions at the initial state and equilibrium time, respectively, $(\mathrm{mg} / \mathrm{L})$. Experimental data were analyzed to determine rate constants of sorption reaction using the non-linear forms of pseudofirst-order Eq. (9) and pseudo-second-order kinetic models Eq. (10)[29].

$q_{\mathrm{t}}=q_{\mathrm{e}}\left(1-e^{-k_{1} t}\right)^{n}$,

$q_{\mathrm{t}}=\frac{k_{2} q_{\mathrm{e}}^{2} t}{1+k_{2} q_{\mathrm{e}} t}$

where $K_{x}$ is the rate constant, $x=1$ pseudo-first-order, $x=2$ pseudo-second-order, $\mathrm{q}_{\mathrm{e}}$ is the amount sorbed at equilibrium and can be determined as follow[43]: 
Fig. 5 a Elimination efficacy. b Point of zero charge $\mathrm{P}_{\mathrm{zpc}}$ of nano-cryptomelane. $\mathbf{c}$ Effect of $\mathrm{pH}$ on sorption of a) $\mathrm{Cs}^{+} \mathrm{b}$ ) $\mathrm{Cs}^{+}$(binary solution) c) $\mathrm{Co}^{2+} \mathrm{d}$ ) $\mathrm{Co}^{2+}$ (binary solution). d. Species distribution of cobalt and cesium at room temperature

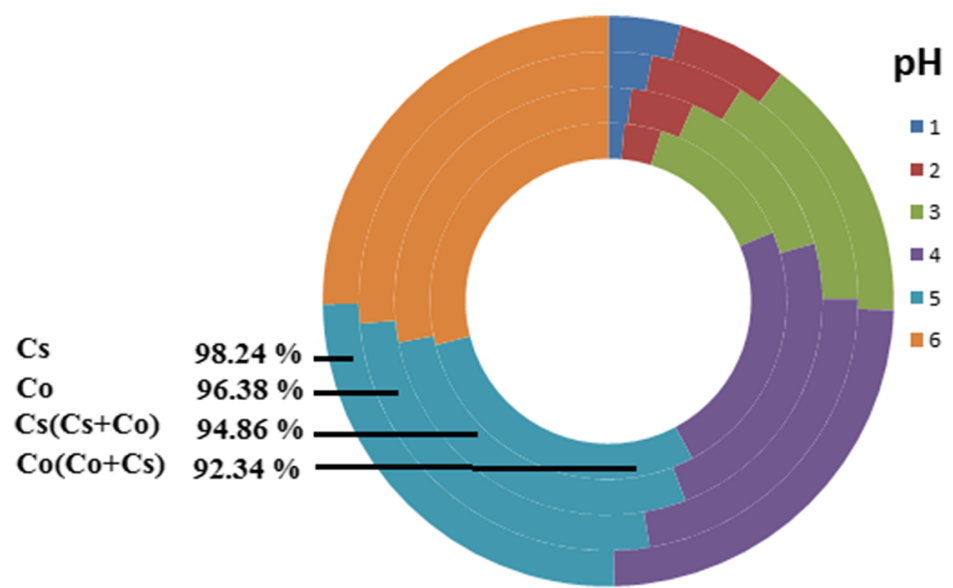

a Elimination efficacy.

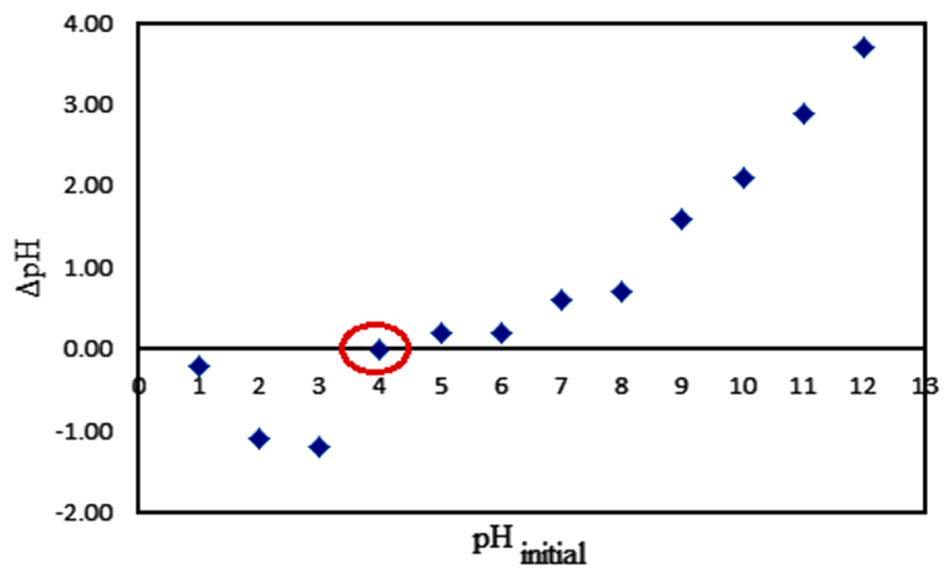

b Point of zero charge $\mathrm{pH}_{\mathrm{zpc}}$ of nano-cryptomelane.
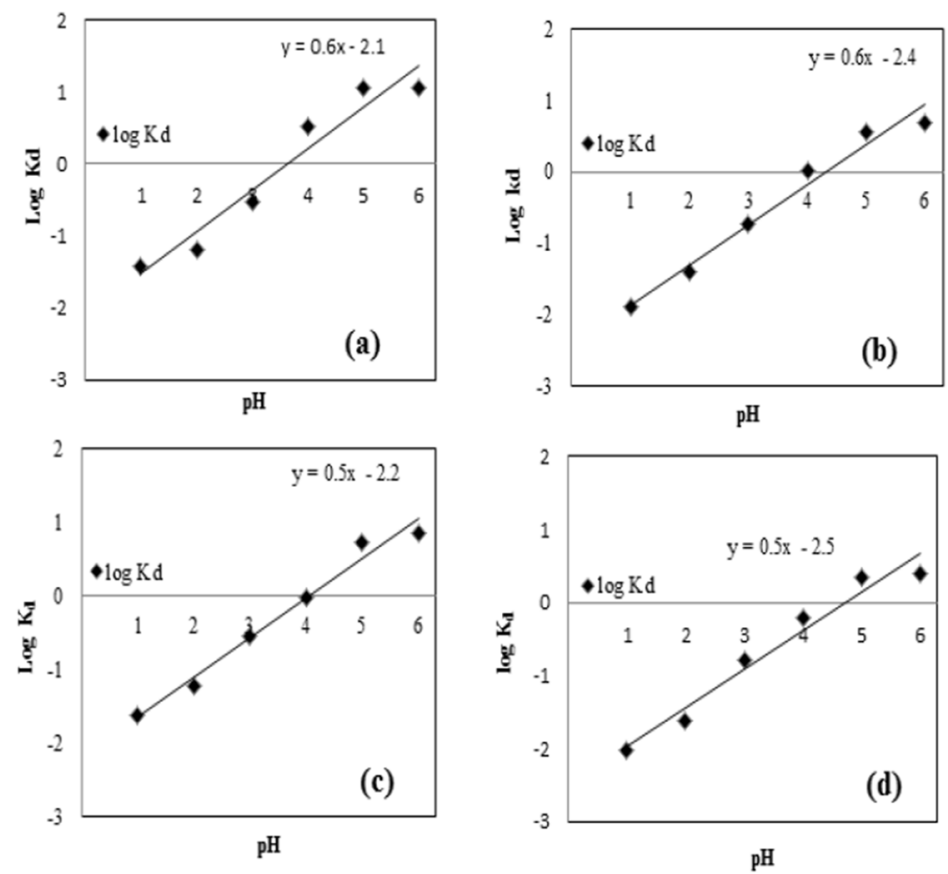

c Effect of $\mathrm{pH}$ on sorption of a) $\mathrm{Cs}^{+}$, b) $\mathrm{Cs}^{+}$(binary solution), c) $\mathrm{Co}^{2+}$ and d) $\mathrm{Co}^{2+}$ (binary solution). 
Fig. 5 (continued)

$$
\begin{array}{ll}
{\left[\mathrm{Cs}^{+}\right]_{\mathrm{TOT}}=0.50 \mathrm{mM}} & \\
{\left[\mathrm{Co}^{2+}\right]_{\mathrm{TOT}}=0.50 \mathrm{mM}} & {\left[\mathrm{Cl}^{-}\right]_{\mathrm{TOT}}=1.50 \mathrm{mM}}
\end{array}
$$

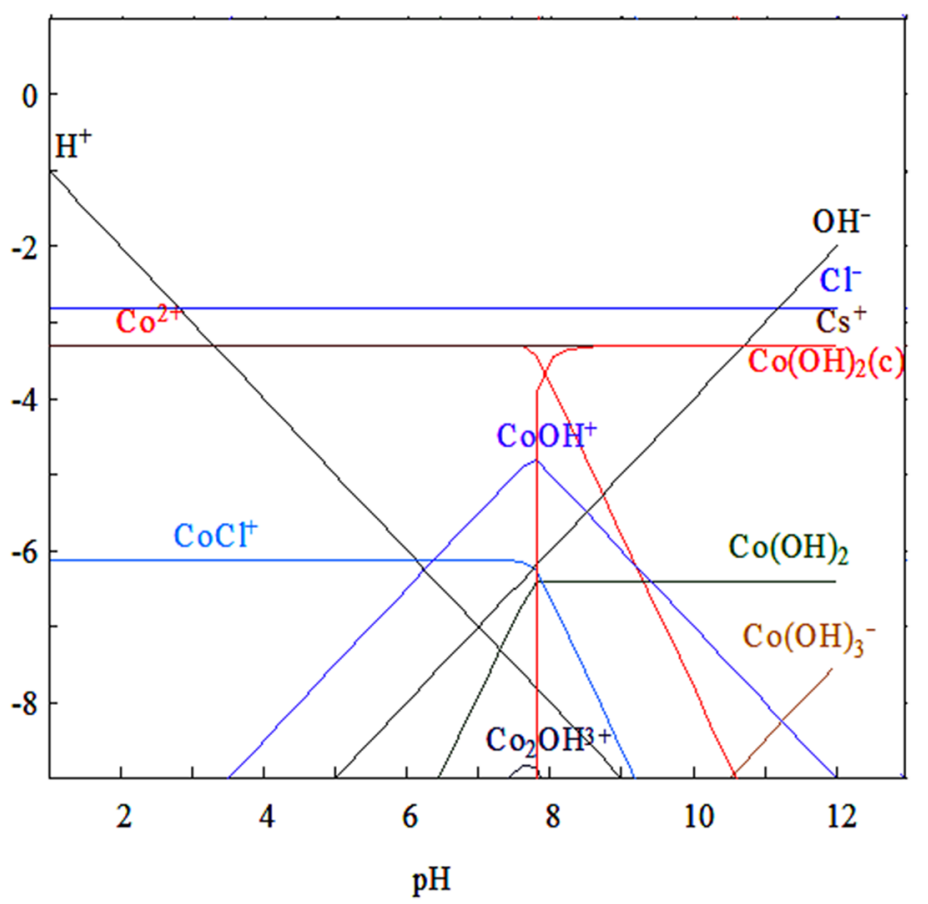

d Speciation of cobalt and cesium at different $\mathrm{pHs}$.

$q_{\mathrm{e}}=\left(C_{i}-C_{\mathrm{e}}\right)\left(\frac{V}{m}\right)$

Figures $7 \mathrm{~b}$ and $8 \mathrm{~b}$ indicate that the residual errors values from pseudo-first-order smaller than those of pseudo-second-order.

Freundlich, Eq. (12), and Langmuir, Eq. (15), isotherm models for multi-component sorption process were used to analyze the experimental data to describe the nature of the sorption sites.

$q_{\mathrm{e}, z}=K_{\mathrm{F}, z} \sum_{z=1}^{N} C_{\mathrm{e}, z}^{1 / n_{z}}$,

where $C_{\mathrm{e}, z}$ is the equilibrium concentrations of the component $z, K_{\mathrm{F}, z}$ is Freundlich constant for the component $z$ indicating sorbent capacity, $\mathrm{mg} / \mathrm{g},(\mathrm{mg} / \mathrm{L})^{1 / n}$ and $n$ is a constant describe the heterogeneity of the surface.

For the sorption of $\mathrm{Co}^{2+}$ and $\mathrm{Cs}^{+}$in a binary system, Freundlich equation becomes;

$q_{\mathrm{e}, \mathrm{Cs}}=K_{\mathrm{F}, \mathrm{Cs}}\left(C_{\mathrm{e}, \mathrm{Cs}}^{1 / n_{\mathrm{Cs}}}+C_{\mathrm{e}, \mathrm{Co}}^{1 / n_{\mathrm{Co}}}\right)$, $q_{\mathrm{e}, \mathrm{Co}}=K_{\mathrm{F}, \mathrm{Co}}\left(C_{\mathrm{e}, \mathrm{Cs}}^{1 / n_{\mathrm{Cs}}}+C_{\mathrm{e}, \mathrm{Co}}^{1 / n_{\mathrm{Co}}}\right)$.

For the competitive sorption of metal ions from a multicomponent system, the extended Langmuir model given by the following equation:

$q_{\mathrm{e}, x}=\frac{q_{\mathrm{m}, x} b_{x} C_{\mathrm{e}, x}}{1+\sum_{j=1}^{N} b_{j} C_{\mathrm{e}, y}}$

where $C_{\mathrm{e}, x}$ and $C_{\mathrm{e}, y}$ are the equilibrium concentrations of the components $x$ and $y$, respectively, $q_{\mathrm{m}, x}, \mathrm{mg} / \mathrm{g}$, is the maximum monolayer sorption capacity for the component $x, q_{\mathrm{e}, \mathrm{x}}$ is the quantity sorbed of component $x, \mathrm{mg} / \mathrm{g}$, at equilibrium in a multicomponent system, $b_{x}$ and $b_{y}, \mathrm{~L} / \mathrm{mg}$, describe the affinity of sorbent towards the sorbates $x$ and $y$, respectively, $y=1,2,3, \ldots, N$, and $N$ is the number of components in the experimental isotherm.

The extended Langmuir equation for the competitive sorption of $\mathrm{Co}^{2+}$ and $\mathrm{Cs}^{+}$in a binary system becomes [45]:

$q_{\mathrm{e}, \mathrm{Cs}}=\frac{q_{\mathrm{m}, \mathrm{Cs}} b_{\mathrm{Cs}} C_{\mathrm{e}, \mathrm{Cs}}}{1+b_{\mathrm{Cs}} C_{\mathrm{e}, \mathrm{Cs}}+b_{\mathrm{Co}} C_{\mathrm{e}, \mathrm{Co}}}$ 

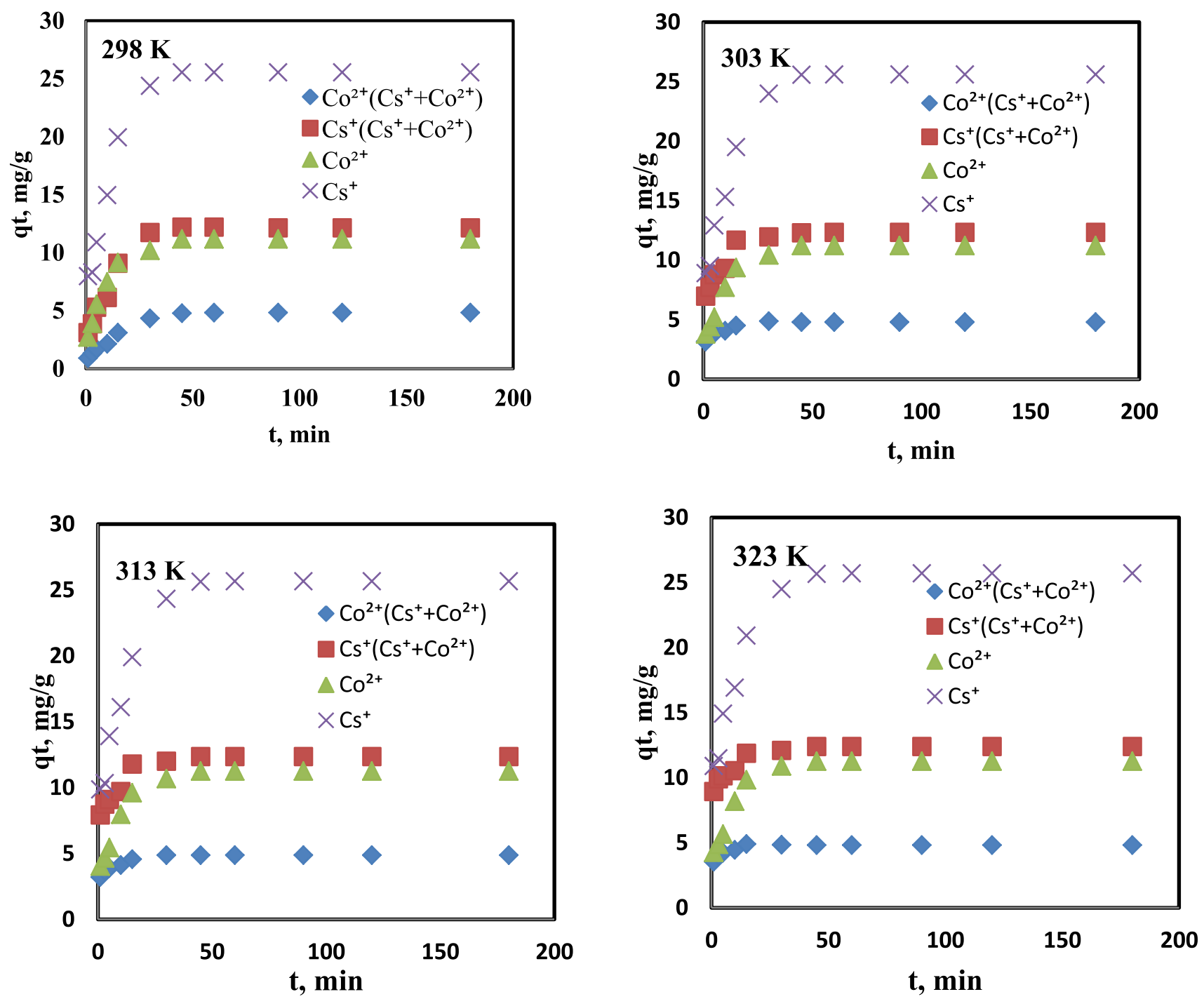

Fig. 6 Effect of time on sorption of Cs+ andCo2+from single and binary solutions

$q_{\mathrm{e}, \mathrm{Co}}=\frac{q_{\mathrm{m}, \mathrm{Co}} b_{\mathrm{Co}} C_{\mathrm{e}, \mathrm{Co}}}{1+b_{\mathrm{Co}} C_{\mathrm{e}, \mathrm{Co}}+b_{\mathrm{Cs}} C_{\mathrm{e}, \mathrm{Cs}}}$.

The nonlinear fitting of the experimental data to Freundlich and Langmuir isotherm models are shown in Figs. 9 and 10 which illustrated that both models could represent the behavior of sorption process. The correlation coefficients of Langmuir are slightly higher than these of Freundlich model (Tables 4 and 5) [46, 47].

\section{Conclusion}

The performance of synthesized nano-cryptomelane for the sequestration of cobaltandcesium ions from their single and binary solutions was studied. The following specific conclusions could be drawn from the above mentioned investigations:

(1) Nano-cryptomelane was prepared using oxidation method and the characteristic results indicated the formation.

(2) The synthesized nano-cryptomelane possesses a tunnel structure with particle size ranged between 4 and $6 \mathrm{~nm}$.

(3) The XRD chart reveals existence of six diffraction peaks recorded at $2 \theta$ of $12.8^{\circ}, 18.5^{\circ}, 28.9^{\circ}, 37.5^{\circ}$, $42^{\circ}$ and $50^{\circ}$ which are specific peaks for nano-cryptomelane.

(4) Seven Raman bands are detected at 183, 286, 330, $386,512,574$, and $753 \mathrm{~cm}^{-1}$ which are specific bands of the Mn-O lattice vibrations within the $(2 \times 2)$ tunnel structure of $\mathrm{MnO}_{6}$ octahedral. 
(5) The SSA of nano-cryptomelane was determined and equal to 299.03 and $\mathrm{D}_{\mathrm{s}}$ was calculated and equal to 2.53 .

(6) The $\mathrm{pH}$ optimum value for sequestration of cesium andcobalt ions was 5 , the percent uptakes take the order $\mathrm{Cs}^{+}>\mathrm{Co}^{2+}$

(7) Kinetic studies illustrate that sorption process more fitted to non-linear pseudo-second-order model.
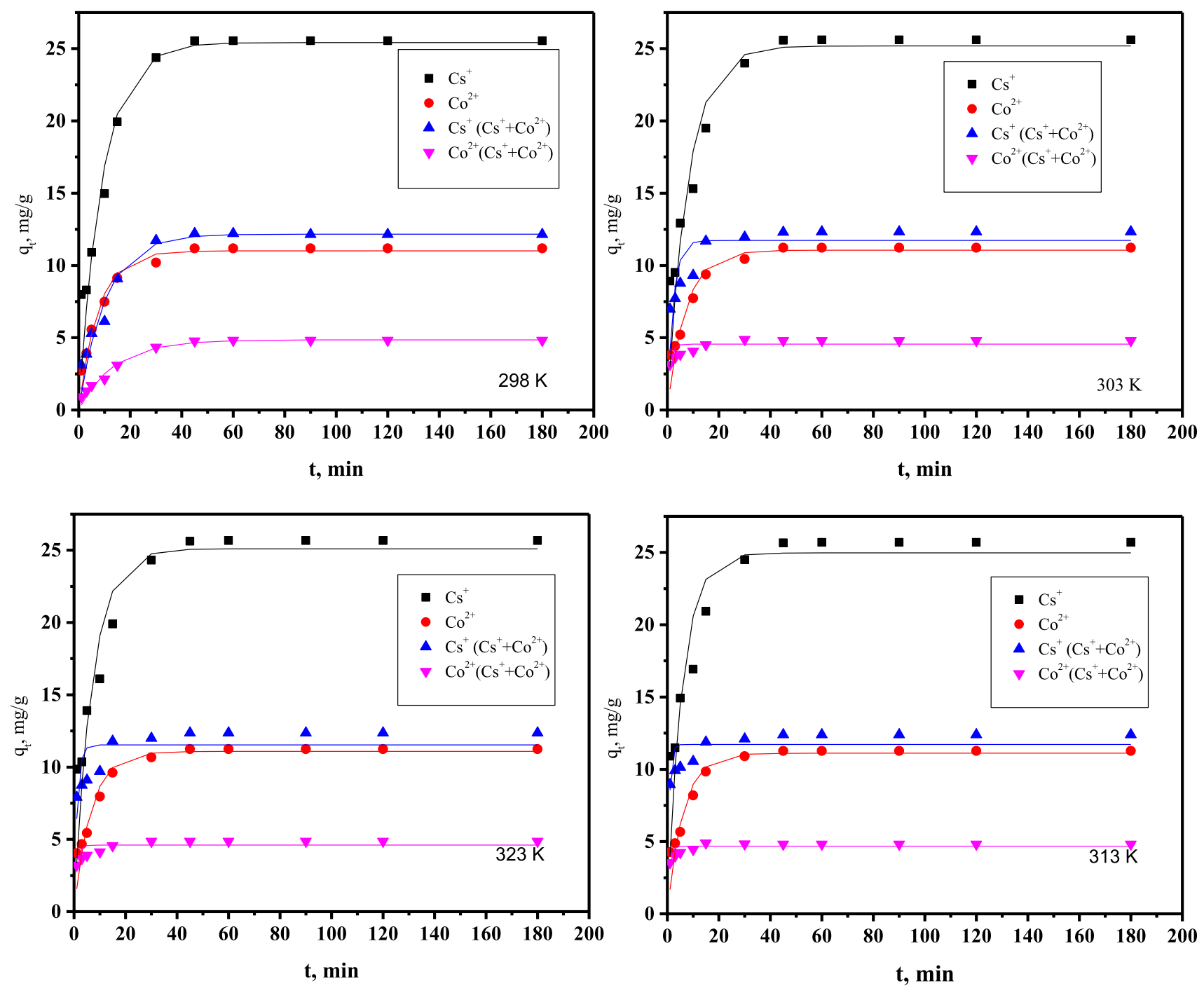

$\mathbf{a}$

Fig. 7 a Non-linear plot of pseudo-first-order kinetic model for sorption of $\mathrm{Cs}^{+}$and $\mathrm{Co}^{2+}$ onto nano-cryptomelane at different temperatures. b Residual errors for non-linear regression of Kinetic data for cesium and cobalt in single and binary solutions in pseudo first order model. 


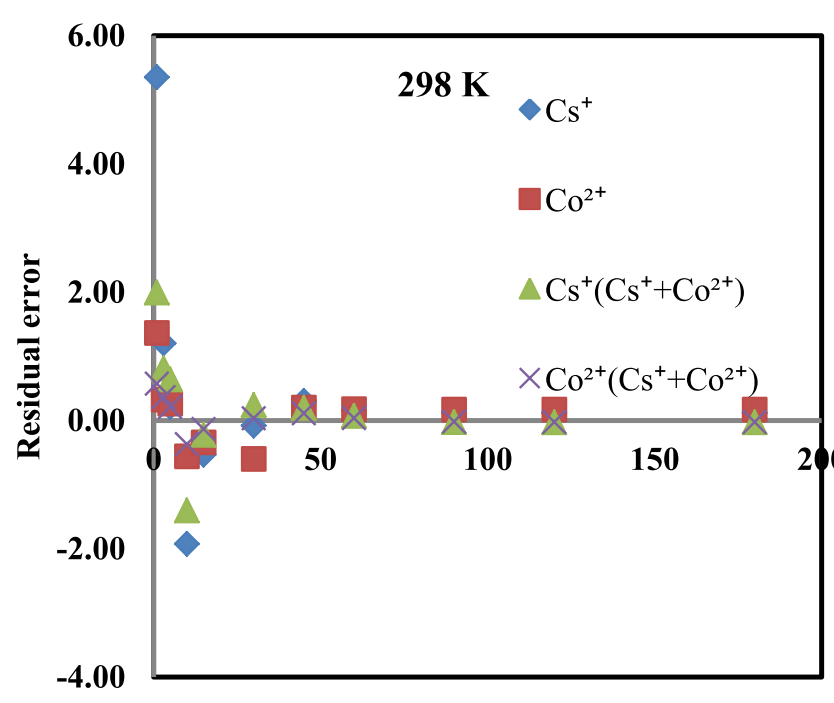

Time, min

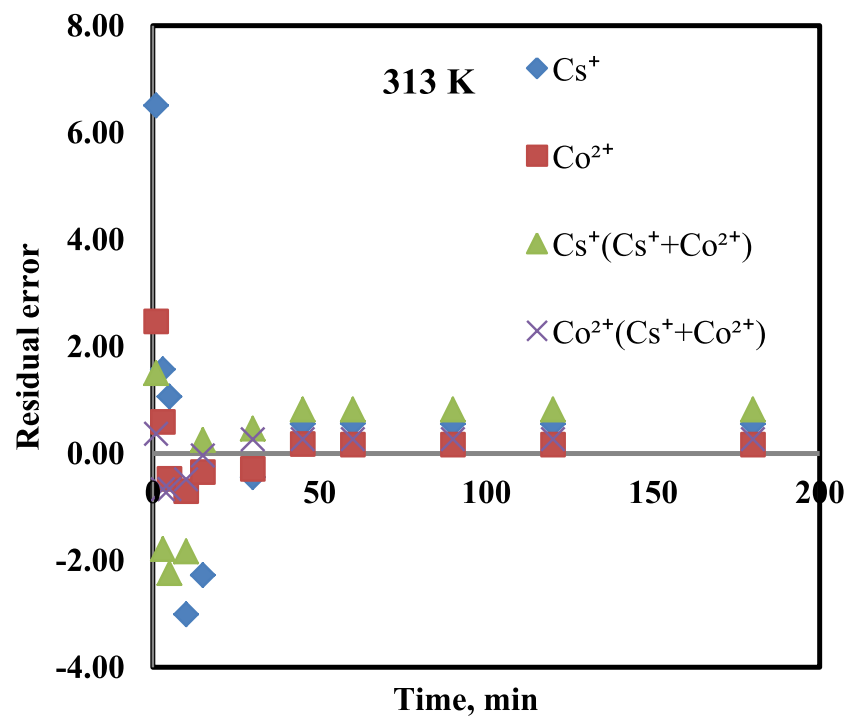

Fig. 7 (continued)
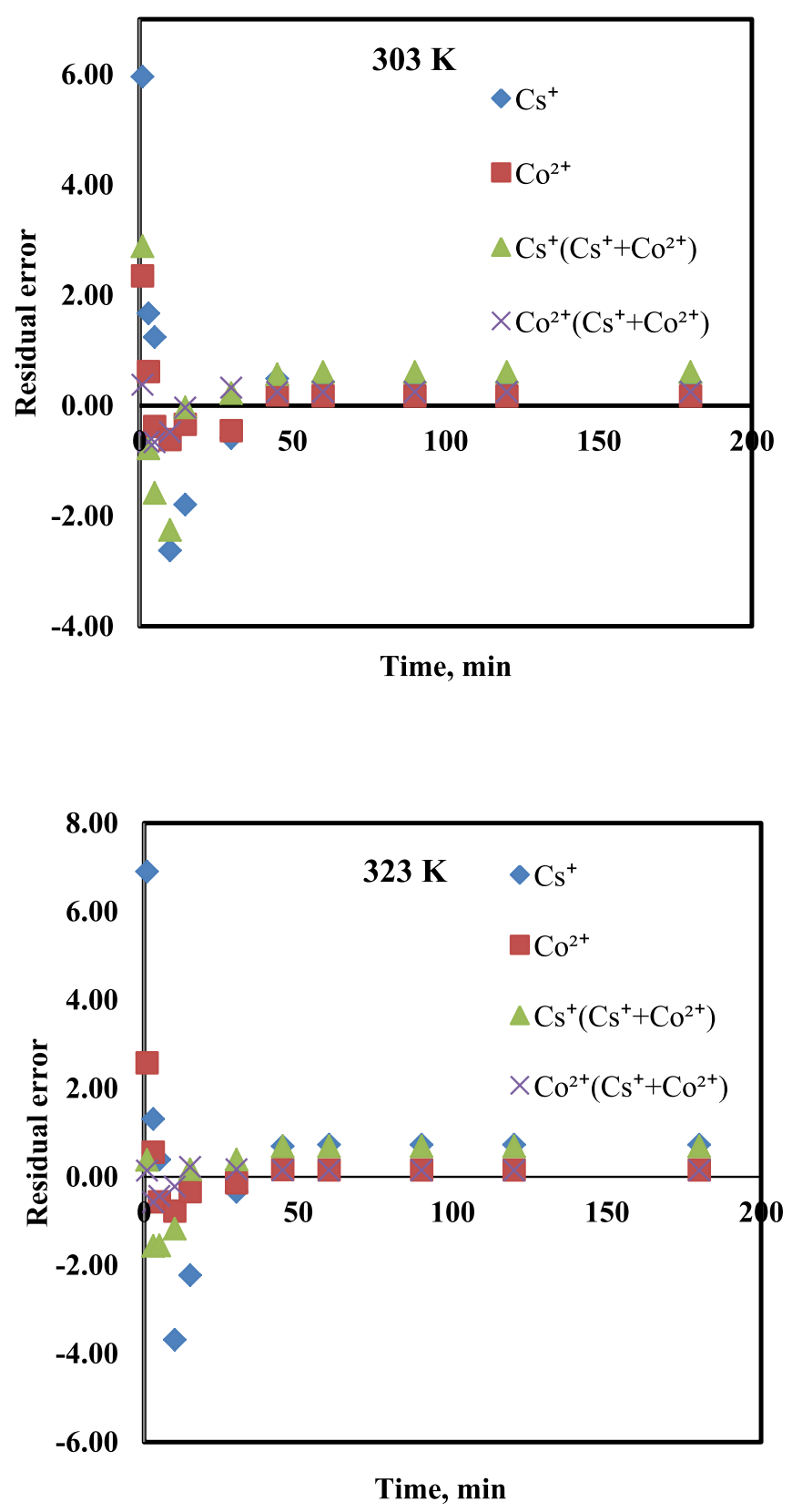

b 

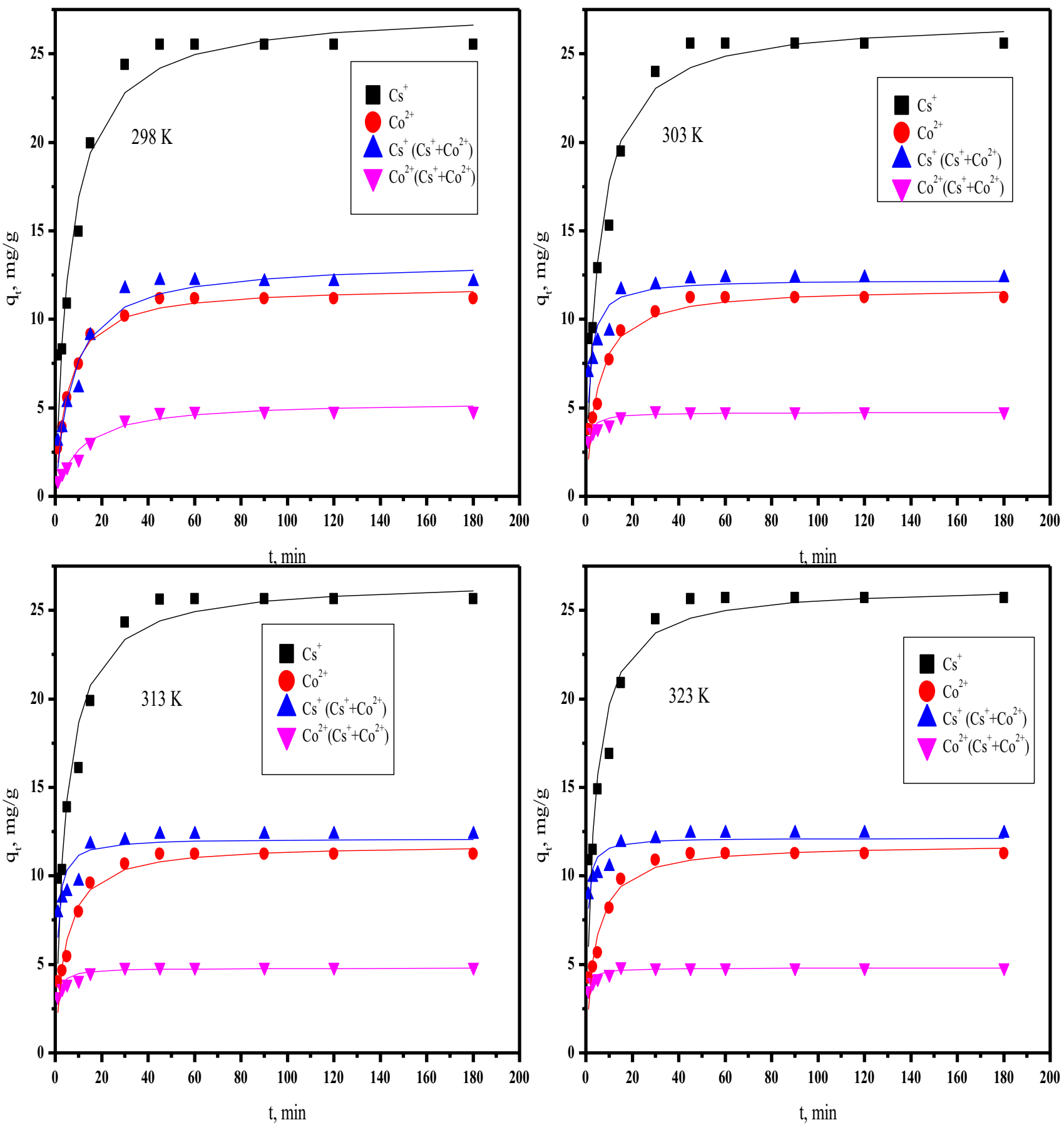

a

Fig. 8 a Non-linear plot of pseudo-second-order kinetic model for sorption of $\mathrm{Cs}^{+}$and $\mathrm{Co}^{2+}$ onto nano-cryptomelane at different temperatures. b Residual errors for non-linear regression of Kinetic data for cesium and cobalt in single and binary solutions in pseudo second order model 

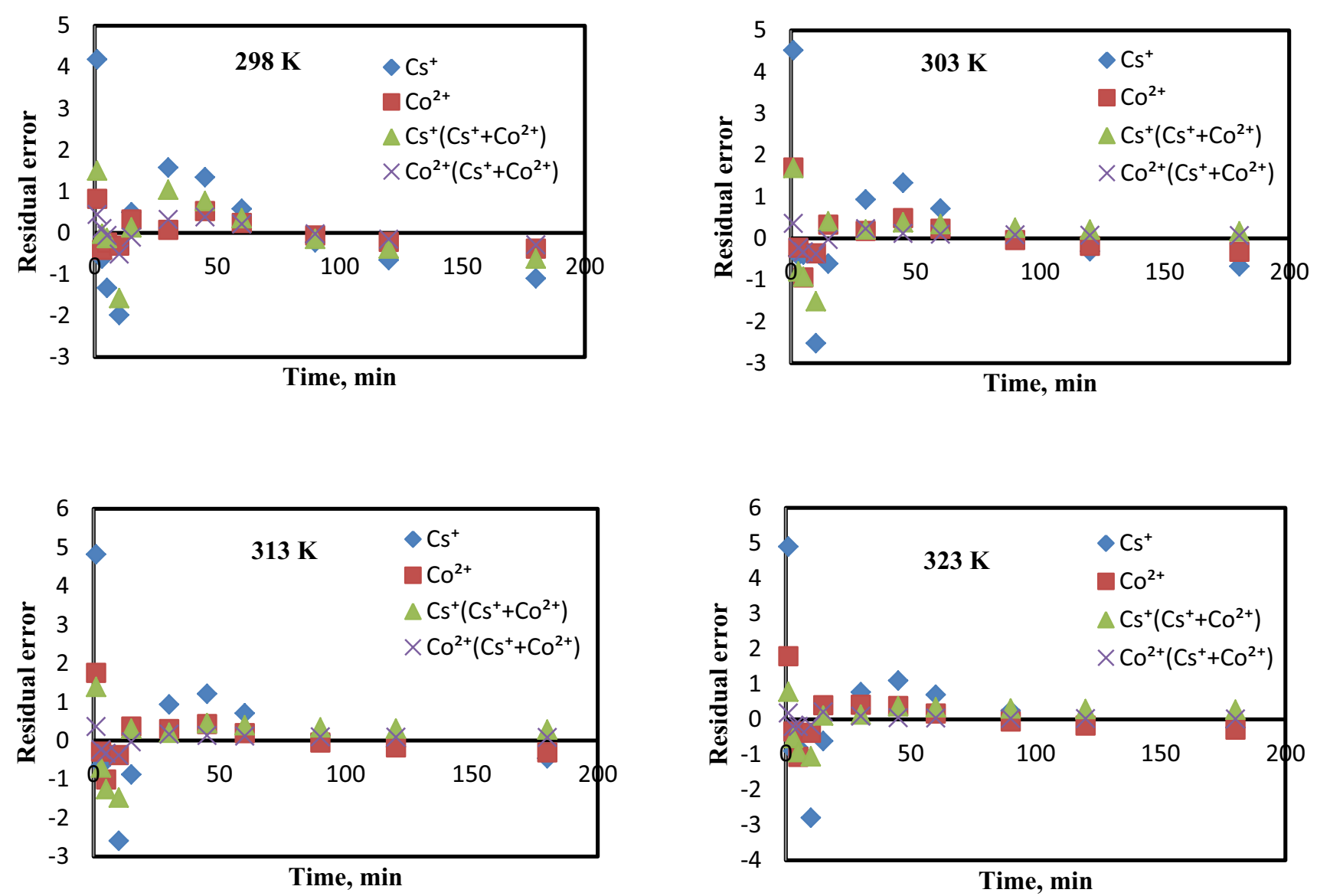

b

Fig. 8 (continued) 
Table 2 Regression parameters of $\mathrm{Co}^{2+}$ and $\mathrm{Cs}^{+}$removal using pseudo first order kinetic model

\begin{tabular}{|c|c|c|c|c|}
\hline & $\mathrm{Cs}^{+}$ & $\mathrm{Cs}^{+}\left(\mathrm{Cs}^{+}+\mathrm{Co}^{2+}\right)$ & $\mathrm{Co}^{2+}$ & $\mathrm{Co}^{2+}\left(\mathrm{Cs}^{+}+\mathrm{Co}^{2+}\right)$ \\
\hline \multicolumn{5}{|l|}{$298 \mathrm{~K}$} \\
\hline $\mathrm{k}_{1}, \min ^{-1}$ & 0.15 & 0.40 & 0.16 & 1.19 \\
\hline $\mathrm{q}_{\mathrm{e}}$, exp. mg/g & 23.78 & 11.74 & 11.18 & 4.78 \\
\hline $\mathrm{q}_{\mathrm{e}}$, calc., mg/g & 22.34 & 10.16 & 9.94 & 4.06 \\
\hline $\mathrm{R}^{2}$ & 0.83 & 0.64 & 0.87 & 0.51 \\
\hline S.E & 1.02 & 0.82 & 0.61 & 0.31 \\
\hline \multicolumn{5}{|l|}{$303 \mathrm{~K}$} \\
\hline $\mathrm{k}_{1}, \min ^{-1}$ & 0.16 & 0.44 & 0.18 & 1.22 \\
\hline $\mathrm{q}_{\mathrm{e}}$, exp. mg/g & 23.99 & 11.94 & 11.23 & 4.80 \\
\hline $\mathrm{q}_{\mathrm{e}}$, calc., mg/g & 22.55 & 10.68 & 10.01 & 4.24 \\
\hline $\mathrm{R}^{2}$ & 0.75 & 0.31 & 0.85 & 0.51 \\
\hline S.E & 1.16 & 0.94 & 0.36 & 0.27 \\
\hline \multicolumn{5}{|l|}{$313 \mathrm{~K}$} \\
\hline $\mathrm{k}_{1}, \min ^{-1}$ & 0.162 & 0.445 & 0.19 & 1.30 \\
\hline $\mathrm{q}_{\mathrm{e}}$, exp. mg/g & 24.32 & 12.04 & 11.25 & 4.81 \\
\hline $\mathrm{q}_{\mathrm{e}}$, calc., $\mathrm{mg} / \mathrm{g}$ & 23.27 & 11.27 & 10.17 & 4.41 \\
\hline $\mathrm{R}^{2}$ & 0.66 & 0.30 & 0.82 & 0.50 \\
\hline S.E & 1.28 & 1.04 & 0.37 & 0.28 \\
\hline \multicolumn{5}{|l|}{$323 \mathrm{~K}$} \\
\hline $\mathrm{k}_{1}, \min ^{-1}$ & 0.163 & 0.45 & 0.20 & 1.46 \\
\hline $\mathrm{q}_{\mathrm{e}}$, exp. mg/g & 24.50 & 12.22 & 11.27 & 4.82 \\
\hline $\mathrm{q}_{\mathrm{e}}$, calc., $\mathrm{mg} / \mathrm{g}$ & 24.22 & 11.99 & 10.31 & 4.51 \\
\hline $\mathrm{R}^{2}$ & 0.52 & 0.55 & 0.80 & 0.59 \\
\hline S.E & 2.36 & 1.51 & 0.37 & 0.29 \\
\hline
\end{tabular}

Table 3 Regression parameters of $\mathrm{Co}^{2+}$ and $\mathrm{Cs}^{+}$removal using pseudo second order kinetic model

\begin{tabular}{|c|c|c|c|c|}
\hline & $\mathrm{Cs}^{+}$ & $\mathrm{Cs}^{+}\left(\mathrm{Cs}^{+}+\mathrm{Co}^{2+}\right)$ & $\mathrm{Co}^{2+}$ & $\mathrm{Co}^{2+}\left(\mathrm{Cs}^{+}+\mathrm{Co}^{2+}\right)$ \\
\hline \multicolumn{5}{|l|}{$298 \mathrm{~K}$} \\
\hline $\mathrm{k}_{1}, \min ^{-1}$ & 0.009 & 0.04 & 0.02 & 0.22 \\
\hline $\mathrm{q}_{\mathrm{e}}$, exp. mg/g & 23.78 & 11.74 & 11.18 & 4.78 \\
\hline $\mathrm{q}_{\mathrm{e}}$, calc., $\mathrm{mg} / \mathrm{g}$ & 24.57 & 11.67 & 11.36 & 4.63 \\
\hline $\mathrm{R}^{2}$ & 0.87 & 0.82 & 0.90 & 0.69 \\
\hline S.E & 0.88 & 0.74 & 0.22 & 1.04 \\
\hline \multicolumn{5}{|l|}{$303 \mathrm{~K}$} \\
\hline $\mathrm{k}_{1}, \min ^{-1}$ & 0.010 & 0.05 & 0.021 & 0.24 \\
\hline $\mathrm{q}_{\mathrm{e}}$, exp. mg/g & 23.99 & 11.94 & 11.23 & 4.8 \\
\hline $\mathrm{q}_{\mathrm{e}}$, calc., $\mathrm{mg} / \mathrm{g}$ & 24.77 & 11.93 & 11.45 & 4.78 \\
\hline $\mathrm{R}^{2}$ & 0.84 & 0.65 & 0.89 & 0.69 \\
\hline S.E & 0.92 & 0.76 & 0.34 & 0.25 \\
\hline \multicolumn{5}{|l|}{$313 \mathrm{~K}$} \\
\hline $\mathrm{k}_{1}, \min ^{-1}$ & 0.011 & 0.06 & 0.022 & 0.28 \\
\hline $\mathrm{q}_{\mathrm{e}}$, exp. mg/g & 24.32 & 12.04 & 11.25 & 4.81 \\
\hline $\mathrm{q}_{\mathrm{e}}$, calc., $\mathrm{mg} / \mathrm{g}$ & 24.96 & 12.31 & 11.55 & 4.90 \\
\hline $\mathrm{R}^{2}$ & 0.81 & 0.8 & 0.88 & 0.73 \\
\hline S.E & 0.95 & 0.78 & 0.34 & 0.25 \\
\hline \multicolumn{5}{|l|}{$323 \mathrm{~K}$} \\
\hline $\mathrm{k}_{1}, \min ^{-1}$ & 0.013 & 0.10 & 0.02 & 0.28 \\
\hline $\mathrm{q}_{\mathrm{e}}$, exp. mg/g & 24.50 & 12.22 & 11.27 & 4.82 \\
\hline $\mathrm{q}_{\mathrm{e}}$, calc., $\mathrm{mg} / \mathrm{g}$ & 24.98 & 12.33 & 11.65 & 5.01 \\
\hline $\mathrm{R}^{2}$ & 0.77 & 0.66 & 0.87 & 0.66 \\
\hline S.E & 0.86 & 0.70 & 0.34 & 0.26 \\
\hline
\end{tabular}



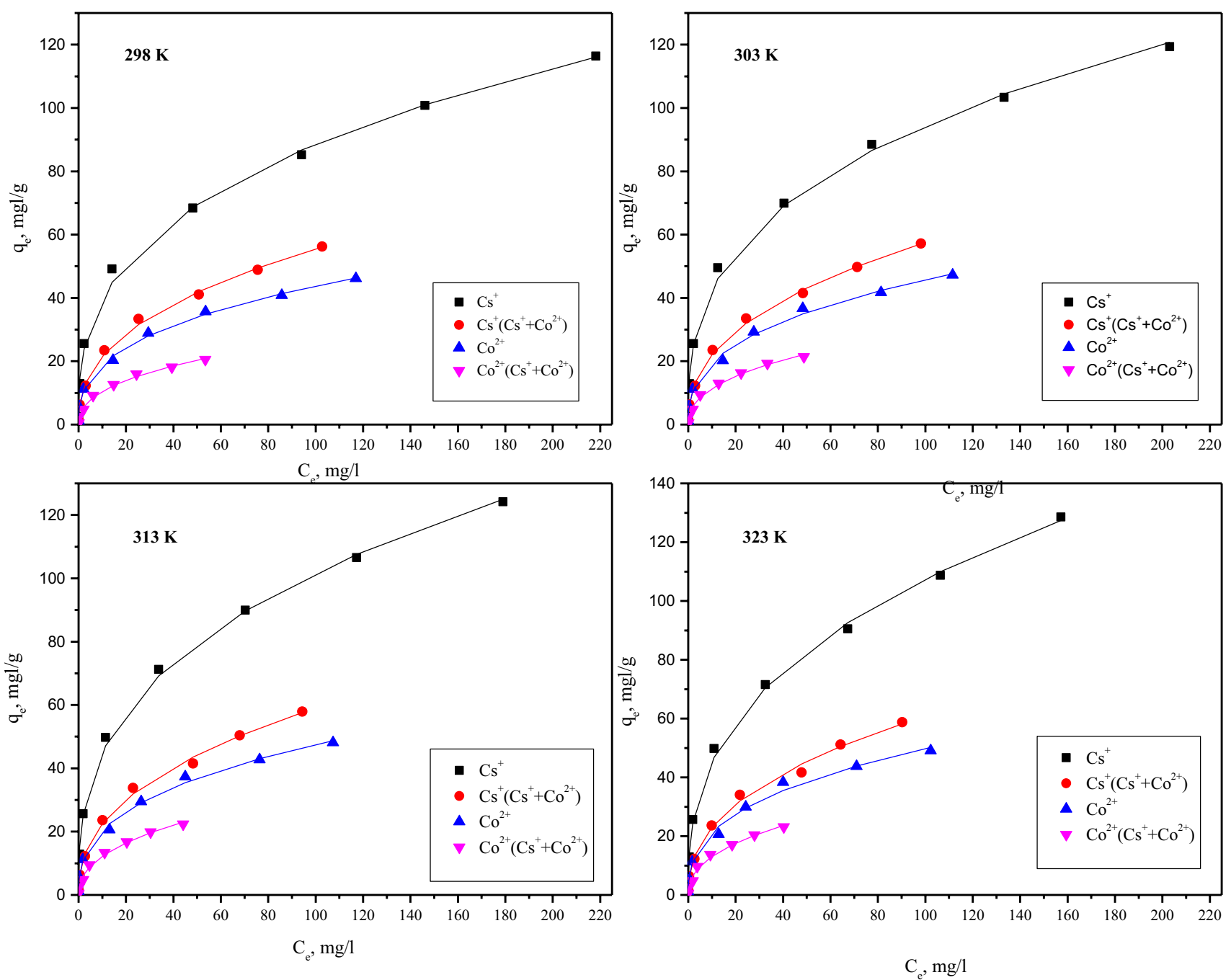

Fig. 9 Non-linear plot of Freundlichisotherm plots for sorption of $\mathrm{Cs}^{+}{ }^{+}$and $\mathrm{Co}^{2+}$ onto nano-cryptomelane at different temperatures 

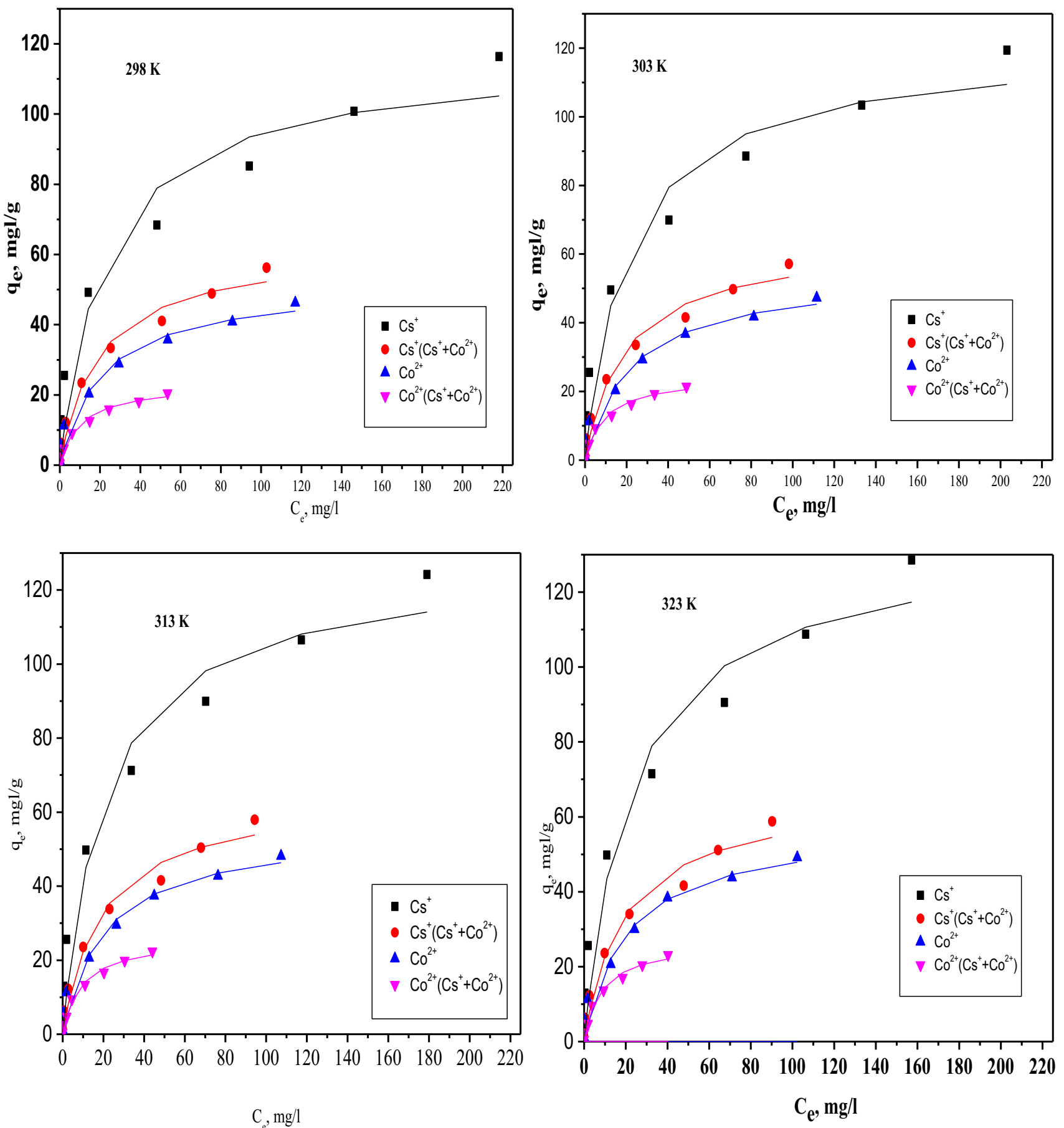

Fig. 10 Non-linear plot of extended Langmuir isotherm plots for sorption of $\mathrm{Cs}^{+}$and $\mathrm{Co}^{2+}$ onto nano-cryptomelane at different temperatures 
Table 4 Freundlich parameters for sorption $\mathrm{Co}^{2+}$ and $\mathrm{Cs}^{+}$onto nanocryptomelane at different temperatures

\begin{tabular}{lclll}
\hline & $\mathrm{Cs}^{+}$ & $\mathrm{Cs}^{+}\left(\mathrm{Cs}^{+}+\mathrm{Co}^{2+}\right)$ & $\mathrm{Co}^{2+}$ & $\mathrm{Co}^{2+}\left(\mathrm{Cs}^{+}+\mathrm{Co}^{2+}\right)$ \\
\hline $298 \mathrm{~K}$ & & & & \\
$1 / \mathrm{n}$ & 0.347 & 0.409 & 0.364 & 0.430 \\
$\mathrm{k}, \mathrm{mg} / \mathrm{g}$ & 17.94 & 7.88 & 8.19 & 3.61 \\
$\mathrm{R}^{2}$ & 0.99 & 0.99 & 0.99 & 1.00 \\
$303 \mathrm{~K}$ & & & & \\
$1 / \mathrm{n}$ & 0.344 & 0.407 & 0.369 & 0.434 \\
$\mathrm{k}, \mathrm{mg} / \mathrm{g}$ & 19.36 & 8.19 & 8.36 & 3.70 \\
$\mathrm{R}^{2}$ & 0.99 & 0.99 & 0.98 & 0.98 \\
$313 \mathrm{~K}$ & & & & \\
$1 / \mathrm{n}$ & 0.354 & 0.412 & 0.370 & 0.440 \\
$\mathrm{k}, \mathrm{mg} / \mathrm{g}$ & 19.87 & 8.25 & 8.66 & 3.81 \\
$\mathrm{R}^{2}$ & 0.98 & 0.98 & 0.99 & 0.99 \\
$323 \mathrm{~K}$ & & & & \\
$1 / \mathrm{n}$ & 0.365 & 0.415 & 0.368 & 0.414 \\
$\mathrm{k}, \mathrm{mg} / \mathrm{g}$ & 19.97 & 8.41 & 9.15 & 4.36 \\
$\mathrm{R}^{2}$ & 0.98 & 0.99 & 0.99 & 0.99 \\
\hline
\end{tabular}

Table 5 Extended Langmuir parameters for sorption $\mathrm{Co}^{2+}$ and $\mathrm{Cs}^{+}$ onto nano-cryptomelane at different temperatures

\begin{tabular}{|c|c|c|c|c|}
\hline & $\mathrm{Cs}^{+}$ & $\mathrm{Cs}^{+}\left(\mathrm{Cs}^{+}+\mathrm{Co}^{2+}\right)$ & $\mathrm{Co}^{2+}$ & $\mathrm{Co}^{2+}\left(\mathrm{Cs}^{+}+\mathrm{Co}^{2+}\right)$ \\
\hline \multicolumn{5}{|l|}{$298 \mathrm{~K}$} \\
\hline Qo, mg/g & 116.10 & 60.82 & 51.73 & 24.01 \\
\hline $\mathrm{b}, \mathrm{L} / \mathrm{mg}$ & 0.044 & 0.046 & 0.048 & 0.071 \\
\hline $\mathrm{R}^{2}$ & 0.95 & 0.98 & 0.96 & 0.97 \\
\hline RL & 0.03 & 0.05 & 0.06 & 0.08 \\
\hline \multicolumn{5}{|l|}{$303 \mathrm{~K}$} \\
\hline Qo, mg/g & 120.72 & 61.56 & 53.15 & 24.75 \\
\hline $\mathrm{b}, \mathrm{L} / \mathrm{mg}$ & 0.048 & 0.047 & 0.049 & 0.072 \\
\hline $\mathrm{R}^{2}$ & 0.96 & 0.97 & 0.96 & 0.97 \\
\hline RL & 0.025 & 0.052 & 0.06 & 0.08 \\
\hline \multicolumn{5}{|l|}{$313 \mathrm{~K}$} \\
\hline Qo, mg/g & 127.27 & 61.73 & 54.79 & 25.75 \\
\hline $\mathrm{b}, \mathrm{L} / \mathrm{mg}$ & 0.0480 & 0.0513 & 0.050 & 0.074 \\
\hline $\mathrm{R}^{2}$ & 0.96 & 0.98 & 0.96 & 0.97 \\
\hline RL & 0.025 & 0.048 & 0.05 & 0.08 \\
\hline \multicolumn{5}{|l|}{$323 \mathrm{~K}$} \\
\hline Qo, mg/g & 130.96 & 63.10 & 56.45 & 26.40 \\
\hline $\mathrm{b}, \mathrm{L} / \mathrm{mg}$ & 0.0490 & 0.0520 & 0.052 & 0.078 \\
\hline $\mathrm{R}^{2}$ & 0.96 & 0.97 & 0.96 & 0.97 \\
\hline RL & 0.025 & 0.048 & 0.05 & 0.08 \\
\hline
\end{tabular}

Funding Open access funding provided by The Science, Technology \& Innovation Funding Authority (STDF) in cooperation with The Egyptian Knowledge Bank (EKB).
Open Access This article is licensed under a Creative Commons Attribution 4.0 International License, which permits use, sharing, adaptation, distribution and reproduction in any medium or format, as long as you give appropriate credit to the original author(s) and the source, provide a link to the Creative Commons licence, and indicate if changes were made. The images or other third party material in this article are included in the article's Creative Commons licence, unless indicated otherwise in a credit line to the material. If material is not included in the article's Creative Commons licence and your intended use is not permitted by statutory regulation or exceeds the permitted use, you will need to obtain permission directly from the copyright holder. To view a copy of this licence, visit http://creativecommons.org/licenses/by/4.0/.

\section{References}

1. Saleh HM, Moussa HR, Mahmoud HH et al (2020) Progress in Nuclear Energy Potential of the submerged plant Myriophyllum spicatum for treatment of aquatic environments contaminated with stable or radioactive cobalt and cesium. Prog Nucl Energy 118:103147

2. Wang $Z$ et al (2022) Application of carbon dots and their composite materials for the detection and removal of radioactive ions: a review. Chemosphere 287:132313

3. Attallah MF, Metwally SS, Moussa SI, Soliman MA (2019) Environmental impact assessment of phosphate fertilizers and phosphogypsum waste: elemental and radiological effects. Microchem J 146:789-797

4. Anirudhan TS, Shainy F, Deepa JR (2019) Effective removal of Cobalt ( II ) ions from aqueous solutions and nuclear industry wastewater using sulfhydryl and carboxyl functionalised magnetite nanocellulose composite : batch adsorption studies. Chem Ecol 35:235-255

5. Khani H, Rofouei MK, Arab P et al (2010) Multi-walled carbon nanotubes-ionic liquid-carbon paste electrode as a super selectivity sensor: application to potentiometric monitoring of mercury ion (II). J Hazard Mater 183:402-409

6. Saleh TA, Gupta VK (2012) Synthesis and characterization of alumina nano-particles polyamide membrane with enhanced flux rejection performance. Sep Purif Technol 89:245-251

7. Tofan L, Teodosiu C, Paduraru C, Wenkert R (2013) Cobalt (II) removal from aqueous solutions by natural hemp fibers: batch and fixed-bed column studies. Appl Surf Sci 285:33-39

8. Gupta VK, Kumar R, Nayak A et al (2013) Adsorptive removal of dyes from aqueous solution onto carbon nanotubes: a review. Adv Colloid Interface Sci 193:24-34

9. Gupta VK, Nayak A, Agarwal S (2015) Bioadsorbents for remediation of heavy metals: current status and their future prospects. Environ Eng Res 20:1-18

10. Metwally SS, Hassan HS, Samy NM (2019) Impact of environmental conditions on the sorption behavior of ${ }^{60} \mathrm{Co}$ and ${ }^{152+154} \mathrm{Eu}$ radionuclides onto polyaniline/zirconium aluminate composite. $\mathbf{J}$ Mol Liq 287:110941

11. Robati D, Mirza B, Rajabi M et al (2016) Removal of hazardous dyes-BR 12 and methyl orange using graphene oxide as an adsorbent from aqueous phase. Chem Eng J 284:687-697

12. Srivastava V, Sharma YC, Sillanpää M (2015) Application of nano-magnesso ferrite $\left(\mathrm{n}-\mathrm{MgFe}_{2} \mathrm{O}_{4}\right)$ for the removal of $\mathrm{Co}^{2+}$ ions from synthetic wastewater: Kinetic, equilibrium and thermodynamic studies. Appl Surf Sci 338:42-54

13. Saleh TA, Gupta VK (2014) Processing methods, characteristics and adsorption behavior of tire derived carbons: a review. Adv Colloid Interface Sci 211:93-101

14. Metwally SS, Ayoub RR, Aly HF (2014) Utilization of low-cost sorbent for removal and separation of ${ }^{134} \mathrm{Cs},{ }^{60} \mathrm{Co}$ and ${ }^{152+154} \mathrm{Eu}$ 
radionuclides from aqueous solution. J Radioanal Nucl Chem 302:441-449

15. Nilchi A, Saberi R, Moradi M et al (2011) Adsorption of cesium on copper hexacyanoferrate-PAN composite ion exchanger from aqueous solution. Chem Eng J 172:572-580

16. Shakir K, Sohsah M, Soliman M (2007) Removal of cesium from aqueous solutions and radioactive waste simulants by coprecipitate flotation. Sep Purif Technol 54:373-381

17. Metwally SS, Rizk HE, Gasser MS (2017) Biosorption of strontium ions from aqueous solution using modified eggshell materials. Radiochim Acta 105:1021-1031

18. Yu S et al (2021) Recent advances in metal-organic framework membranes for water treatment: A review. Sci Total Environ 800: 149662

19. Yu S et al (2022) MXenes as emerging nanomaterials in water purification and environmental remediation. Sci Total Environ 811:152280

20. Rizk HE, Ahmed IM, Metwally SS (2018) Selective sorption and separation of molybdenum ion from some fission products by impregnated perlite. Chem Eng Process Intensif 124:131-136

21. Li H, Liu F, Zhu M et al (2015) Structure and properties of Codoped cryptomelane and its enhanced removal of $\mathrm{Pb}^{2+}$ and $\mathrm{Cr}^{3+}$ from wastewater. J Environ Sci 34:77-85

22. Metwally SS, Hassan RS, El-Masry EH, Borai EH (2018) Gamma-induced radiation polymerization of kaolin composite for sorption of lanthanum, europium and uranium ions from lowgrade monazite leachate. J Radioanal Nucl Chem 315:39-49

23. Hua M, Zhang S, Pan B et al (2012) Heavy metal removal from water/wastewater by nanosized metal oxides: a review. J Hazard Mater 211:317-331

24. Ghaly M, El-Dars FMSE, Hegazy MM, Abdel Rahman RO (2016) Evaluation of synthetic Birnessite utilization as a sorbent for cobalt and strontium removal from aqueous solution. Chem Eng J 284:1373-1385

25. Metwally SS, Ghaly M, El-Sherief EA (2017) Physicochemical properties of synthetic nano-birnessite and its enhanced scavenging of $\mathrm{Co}^{2+}$ and $\mathrm{Sr}^{2+}$ ions from aqueous solutions. Mater Chem Phys 193:63-72

26. Sun L, Cao Q, Hu B et al (2011) Synthesis, characterization and catalytic activities of vanadium-cryptomelane manganese oxides in low-temperature $\mathrm{NO}$ reduction with $\mathrm{NH}_{3}$. Appl Catal A 393:323-330

27. Koivula R, Pakarinen J, Sivenius M et al (2009) Use of hydrometallurgical wastewater as a precursor for the synthesis of cryptomelane-type manganese dioxide ion exchange material. Sep Purif Technol 70:53-57

28. Ghaly M, El-Sherief EA, Metwally SS, Saad EA (2018) Utilization of nano-cryptomelane for the removal of cobalt, cesium and lead ions from multicomponent system: Kinetic and equilibrium studies. J Hazard Mater 352:1-16

29. Sun M, Yu L, Ye F et al (2011) Rapid synthesis of cryptomelanetype manganese oxide under ultrasonic process. Mater Lett 65:3184-3186

30. Liu J, Makwana V, Cai J et al (2003) Effects of alkali metal and ammonium cation templates on nanofibrous cryptomelane-type manganese oxide octahedral molecular sieves (OMS-2). J Phys Chem B 107:9185-9194

31. Villegas JC, Garces LJ, Gomez S et al (2005) Particle size control of cryptomelane nanomaterials by use of $\mathrm{H}_{2} \mathrm{O}_{2}$ in acidic conditions. Chem Mater 17:1910-1918
32. Deng Y-Q, Zhang T, Au C-T, Yin S-F (2014) Oxidation of p-chlorotoluene to $\mathrm{p}$-chlorobenzaldehyde over manganese-based octahedral molecular sieves of different morphologies. Catal Commun 43:126-130

33. Cheney MA, Birkner NR, Ma L et al (2006) Synthesis and characterization of inorganic double helices of cryptomelane nanomaterials. Colloids Surf A 289:185-192

34. Moamen OAA, Hassan HS, Zaher WF (2020) Taguchi L16 optimization approach for simultaneous removal of $\mathrm{Cs}^{+}$and $\mathrm{Sr}^{2+}$ ions by a novel scavenger. Ecotoxicol Environ Saf 189:110013

35. Wu MK (1996) The roughness of aerosol particles: surface fractal dimension measured using nitrogen adsorption. Aerosol Sci Technol 25:392-398

36. Wang H, Tan J, Ge Y et al (2020) Pore morphology and fractal dimension of ash deposited in catalyst diesel particulate filter. Environ Sci Pollut Res 27:11026-11037

37. Said S, Riad M, Helmy M et al (2014) Effect of the different preparation methods on the characterization and the catalytic activity of the nano-structured cryptomelane materials. Chem Mater Res 6:27-41

38. Sada K, Senthilkumar B, Barpanda P (2019) Cryptomelane $K_{1.33}$ $\mathrm{Mn}_{8} \mathrm{O}_{16}$ as a cathode for rechargeable aqueous zinc-ion batteries. J Mater Chem A 7:23981-23988

39. Gao T, Glerup M, Krumeich F et al (2008) Microstructures and spectroscopic properties of cryptomelane-type manganese dioxide nanofibers. J Phys Chem C 112:13134-13140

40. Ramirez-Castro C, Torres-Gonzalez LC (2019) Synthesis and characterization of cryptomelane for use in electrochemical capacitors. ECS Trans 15:91-97

41. Tyagi U (2022) Enhanced adsorption of metal ions onto Vetiveria zizanioides biochar via batch and fixed bed studies. Bioresource Technol 345:126475

42. El-Gammal B et al (2012) Verification of double-shell model for sorption of cesium, cobalt, and europium ions on poly-acrylonitrile-based Ce (IV) phosphate from aqueous solutions. Desalin Water Treat 46(1-3): 124-138

43. Wang S et al (2022) Effect of Shewanella oneidensis MR-1 on U (VI) sequestration by montmorillonite. J Environ Radioact 242:106798

44. Panagiotou E, Kafa N, Koutsokeras L et al (2018) Turning calcined waste egg shells and wastewater to Brushite: phosphorus adsorption from aqua media and anaerobic sludge leach water. $\mathbf{J}$ Clean Prod 178:419-428

45. Steffen V, da Silva EA, Evangelista LR, Cardozo-Filho L (2018) Phenomenological adsorption isotherm for a binary system based on Poisson-Boltzmann equation. Surf Interfaces 10:50-57

46. Liu F et al (2022) Insight into the performance and mechanism of persimmon tannin functionalized waste paper for $\mathrm{U}(\mathrm{VI})$ and $\mathrm{Cr}$ (VI) removal. Chemosphere 287:132199

47. Yang $\mathrm{H}$ et al (2021) Functionalized iron-nitrogen-carbon electrocatalyst provides a reversible electron transfer platform for efficient uranium extraction from seawater. Adv Mater 33(51):2106621

Publisher's Note Springer Nature remains neutral with regard to jurisdictional claims in published maps and institutional affiliations. 